\title{
Are community music therapy principles relevant to my work with large groups of older adults in a residential care facility?
}

A thesis submitted in partial fulfilment of the requirements for the degree of Master of Music Therapy at Victoria University of Wellington

Hazel Barrett

2019 


\begin{abstract}
$\underline{\text { Abstract }}$
This research focuses on my student practicum placement at a residential care home offering rest home, hospital and specialist dementia care for older people. A significant part of my work at the home was facilitating large, open groups, as ensuring the maximum number of residents could participate in music therapy each week was a priority for the facility. Due to my background in community music, which included work in care homes, I was interested in whether community music therapy principles would have relevance in this context. I wanted to improve my practice and add value to my work and in doing so I also hoped to contribute to the wider conversation around the distinction between community music and community music therapy, and how these two disciplines can enhance and support each other.
\end{abstract}

Using an interpretivist framework I engaged in action research, an orientation towards the research process which focuses on real-world change. I conducted three action cycles, collecting data for each cycle over a period of approximately six weeks. I then used thematic analysis to examine this data. My main data source was my practice notes, which included reflections and ideas for improvement. I also drew on the community music therapy literature to develop my practice. Based on emerging themes, I generated actions I could take in the next cycle to advance and improve my practice.

I found that large group music therapy sessions can provide the opportunity for participants, both staff and residents, to experience a shared social space which enables moments of connection and promotes inclusion, creativity, self-determination, and expanded identities. This suggests that the groups had therapeutic value for the participants. I discuss identified differences between my community music and music therapy practice, including the possibilities for individual work and use of music therapy theory. I believe that community music therapy principles were relevant to this work and in particular taking an ecological perspective was significant. Further research into community music therapy in residential care settings is recommended. 


\section{$\underline{\text { Acknowledgements }}$}

I would like to acknowledge and thank those who have made this research possible:

Firstly, Dr Daphne Rickson and Professor Sarah Hoskyns, for all their support, guidance, advice and encouragement through my degree;

My visiting music therapist Rani Heath for her invaluable mentoring;

My interim research supervisor Carolyn Ayson, for her guidance in navigating the initial research proposal;

Māori learning adviser Laura Kamau, for her assistance and direction in creating the final work;

The staff at the facility during my placement, who welcomed me in, made me part of the team and provided me with the benefit of their experience;

The residents I worked with, who welcomed me into their lives and were the best teachers I could have hoped for;

My fellow students - I am grateful to have taken this journey with you;

And my family and friends, for their patience, encouragement and constant support. 


\section{Ethics Approval}

This project was reviewed and approved by the New Zealand School of Music Postgraduate Committee. The Victoria University of Wellington Human Ethics Committee has given generic approval for music therapy students to conduct studies of this type. The music therapy projects have been judged to be low risk and, consequently, are not separately reviewed by any Human Ethics Committees. The Ethics Approval number is 22131. 


\section{$\underline{\text { Table of Contents }}$}

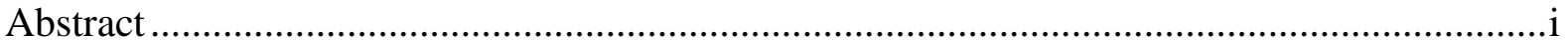

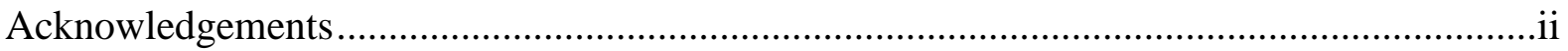

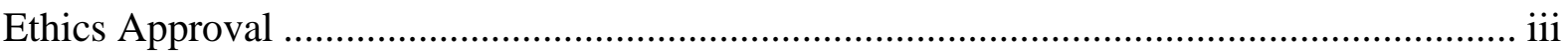

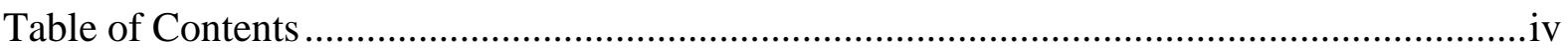

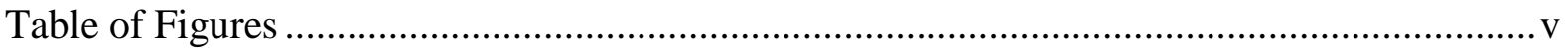

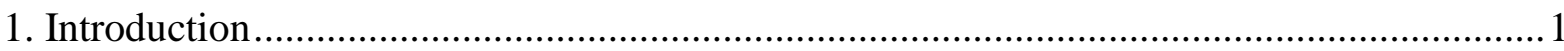

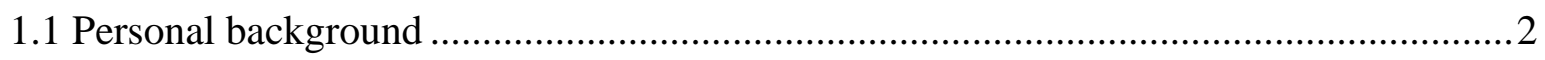

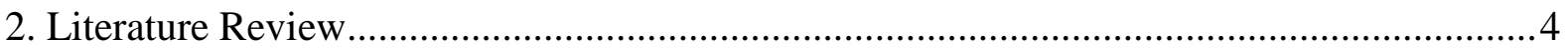

2.1 Older adults in residential care in New Zealand ................................................... 4

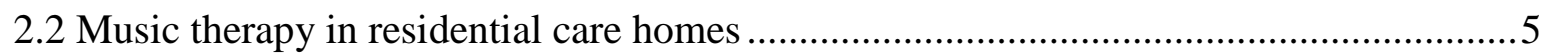

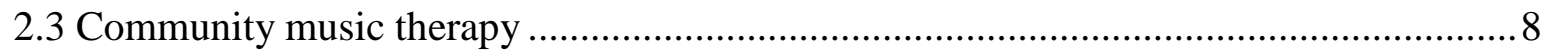

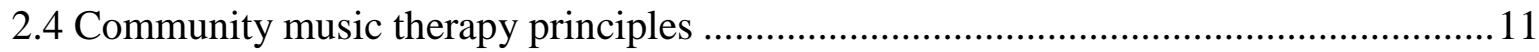

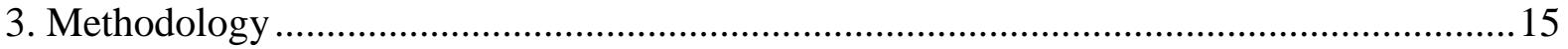

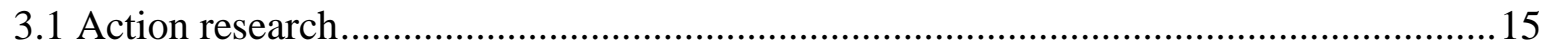

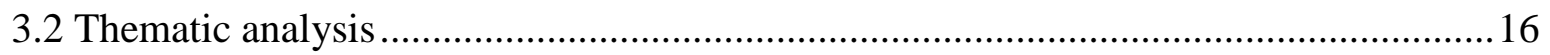

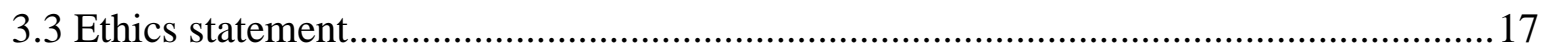

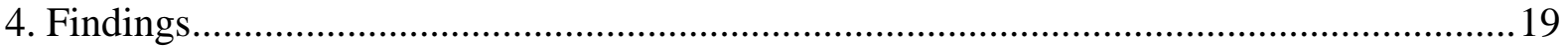

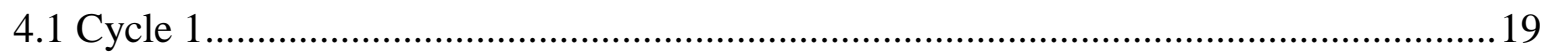

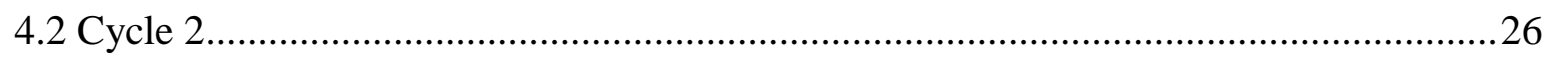

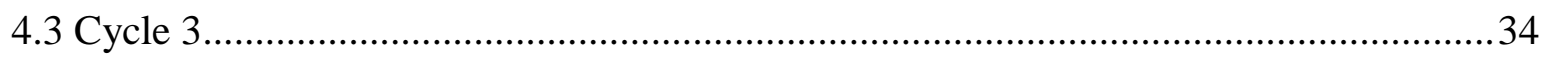

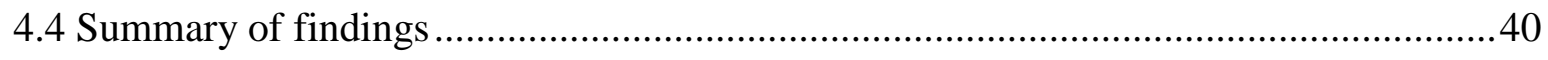

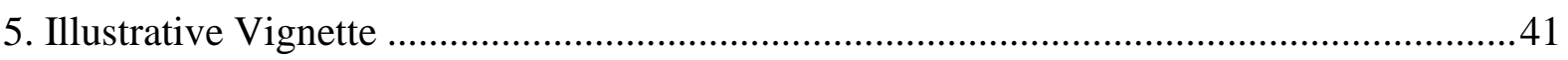

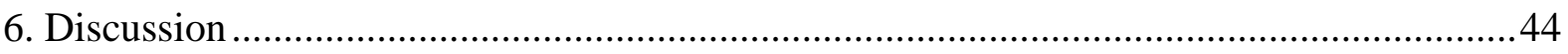

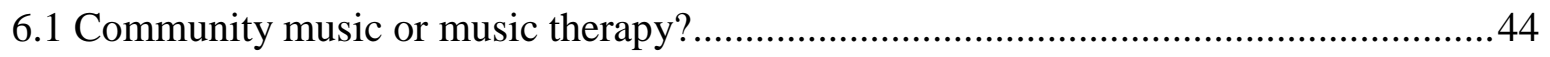

6.2 Community music therapy or clinical music therapy? ............................................4 


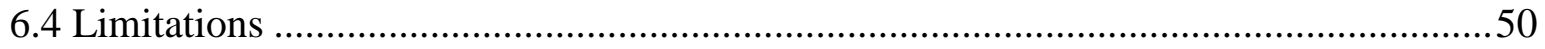

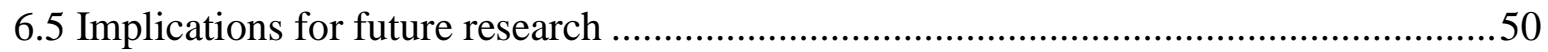

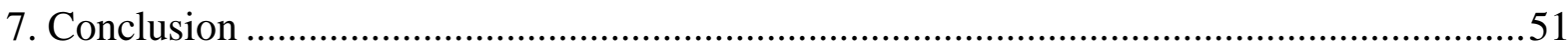

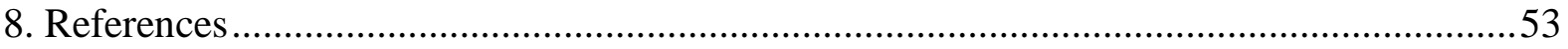

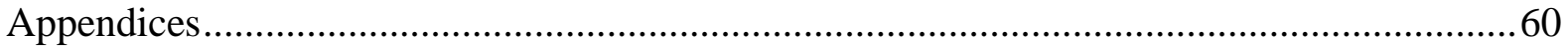

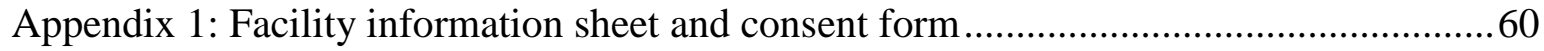

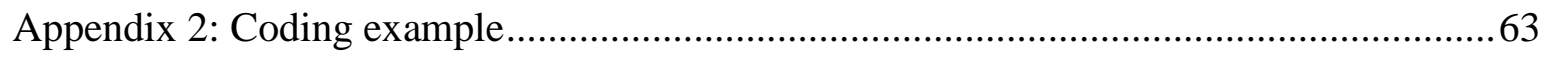

Appendix 3: Detail of the thematic analysis process in each action cycle..........................64

\section{$\underline{\text { Table of Figures }}$}

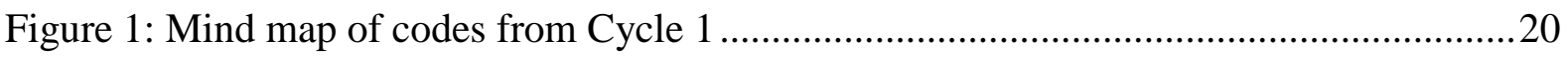

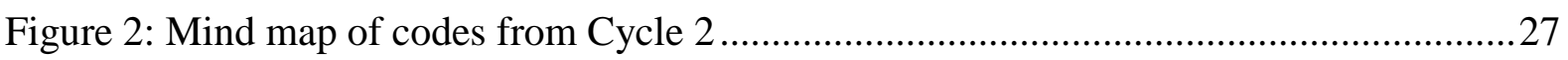

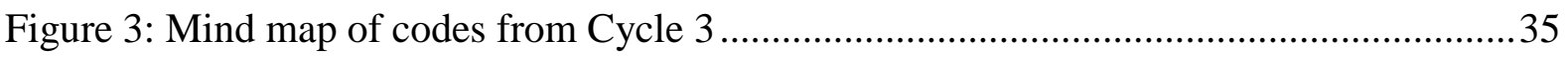




\section{Introduction}

This research has been undertaken as part of a Master of Music Therapy degree, and the context for the project was my practicum placement at a residential care home. This facility offered rest home care, hospital care and specialist dementia care, and hosted respite and day care as well as permanent residents. The home was a large building with several open lounge areas and a dedicated recreation room. There was also a secure wing for residents with dementia who would not be safe living in the main part of the home. The majority of residents were New Zealand European and female.

There were approximately 80 residents at the home, around 15 of whom lived in the secure dementia wing. The majority of residents were older adults, encompassing a range of ages and abilities. Many used wheelchairs or wheeled recliners, whereas others were more mobile. Some residents found it difficult to play musical instruments, such as hand-held percussion, without assistance. Cognitive abilities also varied widely; some residents were living with moderate to severe dementia, whereas other residents had no cognitive impairment. Some residents had mild dementia or similar symptoms but did not live in the secure wing. Residents could experience social isolation, as many of them found it difficult to access social activities unless these were provided for them in the home and they were helped to participate. This was especially true if their family and friends did not live locally.

At the facility I worked closely with the recreation team, who were committed to providing a variety of activities which addressed the residents' spiritual, physical, intellectual, cultural, emotional and sexual selves. A full programme of recreational activities was provided including art, dance, beauty therapy, games and outings. A person-centred and validating approach was used, in particular with residents in the dementia ward, for whom it was felt that reality orientation would generally be unhelpful.

Group sessions were a large component of my work, as ensuring the maximum number of residents could participate in music therapy each week was a priority for the facility. I initially ran four separate large groups, which reduced to three after a few months as one group stabilised with smaller numbers. Each group was held in a different area of the home; sessions were held in the secure dementia unit two or sometimes three times a week, and sessions in the hospital and rest home areas were normally held once a week. The groups were open, and usually had 10-15 residents involved at any one time, and sometimes visitors 
or staff would also join in. Participants would vary from week to week, although each group had some regular attendees who would be present most weeks.

\section{$\underline{1.1 \text { Personal background }}$}

Prior to starting the Master of Music Therapy degree, I worked for several years as a community musician in a variety of settings. One of my roles during this time was cofacilitating music sessions for older adults in care homes. These sessions were a cross between a concert and a sing-along, held in the lounge area and open to any residents, staff and visitors who wished to take part. I was inspired to study music therapy as I felt that music could be employed in more powerful ways than I was using it for in my community work. On starting my second-year music therapy placement at a care home, I found myself again being asked to run music sessions for large groups of older adults in communal areas of the home. I wondered if I would be doing anything differently as a trainee music therapist than in my previous role as a community musician, and whether these groups could really be considered a form of music therapy.

When I completed my BA (Hons) Music undergraduate degree in 2012 I focused my dissertation on community music, and particularly two community music organisations where I regularly volunteered. I attempted to identify some of the key values and aims of community music in order to form a useful definition. The definition I developed was 'Community music encourages creative participation in musical activity, through an inclusive and positive approach, in order to improve the quality of life of the participants and to build living communities' (2012). This encapsulates my view of community music in the forms in which I have experienced it. In the recent Oxford Handbook of Community Music, Schippers (2018) suggests an interpretation of community music as 'a deliberate effort to bring active, inclusive engagement with music-making into communities where this has been forgotten or lost' (p. 23). A focus on inclusion and active participation is key to both definitions.

My understanding of music therapy is that it is 'the planned use of music to assist with the healing and personal growth of people with identified emotional, intellectual, physical or social needs' (Music Therapy New Zealand, 2011). Music therapy has developed a focus on work with individuals or small groups (Aigen, 2014), but recently community music therapy has emerged as an approach which combines aspects of both community music and music therapy. 
I believe that community music practice spans a wide spectrum, and some of this work may be functionally indistinguishable from community music therapy. A number of community music therapy articles have been published in the journal Community Music, such as in the special issue edited by Tsiris (2014a), demonstrating the extent of common interests. However, the focus on 'healing' and 'people with identified ... needs' narrows the range of what can be considered music therapy practice according to the definition above. Pavlicevic and Ansdell (2004) refer to people they have met who have taken the same journey as I have, moving from community music to music therapy. They suggest that community music therapy may be a way of 'integrating their past and present professional identities in new ways', and that it can provide a 'conceptual umbrella' which is able to grant legitimacy to a wider variety of music therapy practices (Pavlicevic \& Ansdell, 2004, p. 17).

Through my music therapy training I am moving from community musician to music therapist, and this research has taken place in an interim stage, that of music therapy student. When I started my placement I was interested in how I could improve my practice and add value to my work as a student music therapist which would not have been present in my community music work. I wanted to investigate how community music therapy principles may relate to large group work in a residential care home, and whether this framework could help me to develop new skills. Through this research I also hope to contribute to the wider conversation around the distinction between community music and music therapy, and how these two fields can enhance and support one another. 


\section{Literature Review}

\subsection{Older adults in residential care in New Zealand}

The Ministry of Health reports that around 10\% of people aged 75 and over require residential care (Ministry of Health, 2017). Although this percentage has reduced over the last five years, the number of people entering residential care has increased as the New Zealand population ages, and it is estimated that by 2050 around $25 \%$ of the population will be aged 65 years and over (Statistics New Zealand, 2016). Approximately 52\% of people entering long-term residential care in 2016 had dementia, making this one of the leading causes of health loss for older adults (Ministry of Health, 2017). The most recent annual Health and Independence report highlights that 'As our population grows and ages, we are seeing more New Zealanders living with disability, long-term physical and mental health conditions, and increasing multimorbidity (with two or more conditions)' (Ministry of Health, 2018, p. 105).

In a New Zealand healthcare context Te Whare Tapa Whā is an important concept. Te Whare Tapa Whā is a Māori perspective on health which represents the four dimensions of wellbeing. These are taha tinana, physical health; taha wairua, spiritual health; taha whānau, family health; and taha hinengaro, mental health. It was developed by Mason Durie (Durie, 1985, 1998) and has since been recognised by the Ministry of Health. This holistic approach to health is useful when considering how music therapy can best support the health and wellbeing of participants. As Durie wrote in his original article about this approach, 'the incorporation of Māori attitudes and Māori experts into Western health systems should lead to a more comprehensive approach to health problems in New Zealand' (Durie, 1985, p. 486).

In my context, the taha tinana of the residents is tightly controlled and monitored by the home and is a focus for the nursing and caregiving staff. Taha hinengaro, which includes cognition and management of emotions, is often severely affected by residents' conditions such as dementia and Parkinson's disease, and is gradually deteriorating. Music therapy can support all areas of health but can be particularly helpful in strengthening taha whānau and taha wairua, a dimension of health which is often felt to be missing from health services (Ministry of Health, 2015). 
According to Durie, taha whānau represents not only connections to relatives and friends, but also 'social outcomes in the broader context of human relationships and social functioning' (Durie, 2001, p. 244). Music therapy can support residents to develop relationships and participate in social activity, particularly where they are unable to participate in social activities they enjoyed previously. The concept of whanaungatanga, a sense of connection and belonging, is an important aspect of my work in the home. Among the many benefits of singing with elderly patients identified by Clair (2000), she notes that it provides 'a point of human contact with other individuals' (p. 83) and can provide an experience of community, for example through the structure and predictability of familiar songs.

Taha wairua 'has many connotations, including the experience of mutually rewarding encounters between people, a sense of communion with the environment, access to heritage, and cultural integrity' (Durie, 2001, p. 243). Music therapy can be used to support these connections with others, the environment, and culture, and can provide people with an opportunity to express their spiritual selves. Taha wairua also encompasses religious beliefs, and many residents in the home had an identified religious belief; in this area I was able to liaise with the pastoral support worker at the home to ensure that residents had adequate spiritual support.

Te Whare Tapa Whā helps practitioners to maintain a holistic view of health and to ensure that all areas of a person's wellbeing are addressed in their care. This is particularly relevant in a residential care setting where all the needs of the residents should be provided for within the environment of the home. It can also provide a framework for how music therapy can collaborate effectively with other disciplines in residential care.

\subsection{Music therapy in residential care homes}

To find literature relating to music therapy in residential care homes I conducted a search using the key terms "music therapy" and "residential care" or "care home". I then narrowed my results to English language articles in peer-reviewed journals and focused on articles published in the last ten years. In both searches the most prevalent subject was dementia care, which is not surprising when, as noted above, approximately half of older adults in long-term residential care have dementia. These initial results led to further relevant literature through references. 
The literature shows there is interest among the professional communities of nurses and caregivers in using music to improve residents' lives, and to improve not only residents' wellbeing but the wellbeing of those caring for them (Eells, 2014; Mendes, 2015; Ray \& Fitzsimmons, 2014). This indicates a potential willingness of care home staff to participate in music therapy and to learn music techniques they can use with residents. The potential for skill sharing or 'indirect' music therapy practice was discussed at the World Congress of Music Therapy in 2017, showing an interest in 'expanding the role' of music therapists in this setting (McDermott et al., 2018, p. 272). A recent meta-analysis of papers investigating the involvement of care staff in creative arts activities with people with dementia in residential care suggested that arts activities had the potential to 'facilitate enhanced interactions and improve care strategies', leading to the 'recognition and validation of personhood in residents with dementia' (Broome, Dening, Schneider, \& Brooker, 2017, p. 1979).

As well as this informal approach some formal training has been studied. Burrows (2009) reported on a music training programme for care professionals which focused on communication with people with dementia. In their feedback participants described how they had gained confidence and believed the training could increase their job satisfaction, and many requested further training. Interestingly, this training was run by a registered nurse with a specialism in using music in care for people with dementia and a team of community musicians. Music therapist Laura Beer developed and delivered enhanced communication training over twenty times to care home staff and visitors, and considers this training to have improved caregivers' confidence and their understanding that those with advanced dementia still have emotional and spiritual needs (Beer, 2017).

A study by Hsu, Flowerdew, Parker, Fachner, and Odell-Miller (2015) involved care staff in a music therapy programme by showing video clips of individual music therapy sessions to staff members. Only selected parts of the sessions were shown, which reduced the time staff needed to spend and improved patient confidentiality. Data from interviews with caregivers suggested that they found the video presentations useful and these changed the way they interacted with residents.

There is also evidence that taking part in music therapy might improve the relationships between residents and caregivers. Melhuish, Beuzeboc, and Guzmán (2017) investigated the experiences of care home staff taking part in music therapy and dance movement therapy with residents with dementia over a period of six weeks. These were 
relatively large, open groups with 8-12 residents attending each week. They found that staff discovered more about residents' abilities and feelings, learned new skills which impacted their care practice, and increased their sense of connection with the residents. Similar insights were found for those who attended music therapy and those who attended dance movement therapy.

Pavlicevic et al. (2015) studied improvisational music therapy work by six experienced practitioners in dementia care homes. They found music interactions happening on a person-to-person or 'micro' level, a 'meso' level outside the dedicated session time, and a 'macro' level throughout the care home (p. 659). They suggest that community music therapists in a residential care home setting 'strategically ensure that work drifts around the entire social and physical space, throughout the day' (p. 674), contrasting this to an approach where music therapy is only delivered to certain residents in a specific time and place. The metaphor of the 'ripple effect' (from Pavlicevic \& Ansdell, 2004, p. 16) is used to describe this expansion of music therapy work which is embedded in everyday life in the home. They also suggest that residents, staff and visitors can experience expanded identities beyond these roles through taking part in music.

Some studies have focused on the views of care home residents on their experiences in music therapy. Chen, Lin, and Jane (2009) conducted focus groups with nursing home residents in Taiwan about their experience of group music therapy, and found that strength derived from the group dynamic and enhanced quality of life were the main themes identified. McDermott, Orrell, and Ridder (2014) conducted interviews and focus groups with people with dementia living in two care homes in the UK and their families, care home staff, day care clients with dementia and music therapists. The interviews focused on the musical experiences of the people with dementia. They identified three areas in which music has an impact on the individual: it is accessible in the 'here and now', it is linked to identity and personal history, and it builds relationships or 'connectedness' (p. 714). Music was also considered to have short term positive effects on mood and to improve the environment of the care home. Music therapists interviewed identified some challenges of evaluating and communicating the music therapy process, but also benefits such as improved relationships between care staff and residents.

Tuckett, Hodgkinson, Rouillon, Balil-Lozoya, and Parker (2015) conducted focus groups with care staff and family members from three residential care homes about group 
music therapy sessions. Carers noted that the timing of music therapy groups impacted significantly on their day and ability to complete their care tasks. Benefits of music therapy were seen to be that it is an activity and social gathering which promotes cognition and exercise. Although there was no clear agreement on the effects of music therapy, there was a general consensus that more music therapy would be beneficial.

The literature shows that music therapy in a care home environment impacts on, and is impacted by, the wider context in which it takes place. There is evidence that care staff have an interest in music therapy and music techniques, and can enhance their practice by taking part in music therapy sessions or further training. Music therapy is generally seen to increase social connection and whanaungatanga in care homes, and improve understanding of residents' emotional needs and taha wairua. Residents, family members and care staff consider music therapy to be a positive addition to life in a residential care home.

\subsection{Community music therapy}

Gary Ansdell's seminal article 'Community Music Therapy and the winds of change' (2002) was one of the first works to identify and define community music therapy as a distinct approach, and to contrast it to the 'consensus model' of music therapy based on psychotherapeutic methods. Ansdell suggests community music therapy as a 'third way' which combines music therapy and community music approaches. He identifies the guiding principles of community music therapy as happening wherever music or music-making is needed, cultivating musical community in the client's context, and working with the natural tendencies of engagement with music.

The term 'consensus model' may be somewhat misleading, as it seems to suggest that non-community music therapy practice is more homogenous than it truly is. It could also be seen to imply a lack of critical engagement and reflection on practice, a 'consensus' on the way things should be done. Although this term is used widely in the community music therapy literature I have generally used the term 'clinical' music therapy to refer to the more established methods of practice, as I feel this is a more accurate and perhaps less judgemental term.

A clinical music therapy model would arguably characterise the group music sessions I was facilitating as community music, not music therapy. Aigen (2014) identifies some of 
the clinical practices which music therapy adopted as it differentiated itself from other musical activity, including regular meetings held with privacy and confidentiality and working with individuals and small groups in order to have specific individual goals. These do not apply to the large group sessions I was facilitating in communal areas. The American Music Therapy Association's definition of music therapy refers to the 'use of music interventions to accomplish individualized goals' (American Music Therapy Association, 2018). In groups of around 15 residents, who change from week to week, it is not practical to have long-term individual goals for all residents. Some of the modalities often used by music therapists in other settings, such as songwriting and free improvisation, would potentially be inappropriate for large groups with multiple levels of ability where participants do not know each other very well (Eyre \& Lee, 2015).

Community music therapy seemed to be an appropriate therapeutic framework to draw on for my group work for several reasons. The definition of a community music therapist as a 'therapeutic musician in residence' (Ansdell, 2002) was a role that felt comfortable to me, suited the activities which were assigned to me as a student therapist, and was understandable to many residents in the care home. The notion of 'community as client' (Aigen, 2014, p. 150) was especially relevant to my context, where the community was the focus of my group sessions rather than a small number of individuals. Performance is a modality used within community music therapy which is rarely found in other methods. Within my context at the care home, the open nature of the environment meant that passing residents, staff and visitors were often in the role of spectators. This was very different to the traditional model of music therapy happening in a private, dedicated space. Residents may have felt as if they were performing to some degree, and so I felt that I should be aware of how this could impact on the group, in both positive and negative ways. Community music therapy gave me a framework to do this.

The acceptance of community music therapy as a truly therapeutic framework is still under some debate. The common clinical practices identified by Aigen (2014) of private, confidential meetings with individuals or small groups are often missing in community music therapy, causing some to see it as 'a regression for the field' (p. 149). When working with a large group, it is impractical to maintain separate individual goals for each participant, and there is no way to guarantee that a consistent group will regularly attend. When meeting in community spaces privacy and confidentiality can be compromised. 
However, others view community music therapy as an important way to widen music therapy practice, and to include an awareness of music as a social and cultural phenomenon (Ansdell, 2004). Stige (2012) identifies the ecological perspective on which community music therapy is founded as a distinctive element which separates it from other areas of practice. Community music therapy can also been seen as a way to bring music therapy closer to more naturalistic ways of interacting with music, such as learning instruments and performing (Aigen, 2012).

Although a distinction has been drawn by many theorists between community music and community music therapy, the boundary is still unclear. Ansdell, in his original article, distinguished community music therapy from community music by the therapist's 'experience and expertise in working with pathology and its manifestations' (Ansdell, 2002). For an inexperienced therapist, this is a somewhat daunting standard. O'Grady and McFerran (2007a) interviewed community music therapists and community musicians in order to examine the differences between their professions. They identified that community music therapists were more likely to work with people in the acute stages of their illness, to prioritise the individual's ownership and self-expression rather than the final musical product, and to adhere to external ethical guidelines.

In reflecting on her own transition from community musician to music therapist, Powell (2004) considers a community music project to be driven by the performance or product created, whereas in community music therapy the performance is a 'by-product' of the therapeutic process (p. 181). She also identifies the process in community music therapy as being created and owned by the community, more so than a community music project. However, community musicians may not agree with this characterisation; community music theorist Lee Higgins stresses that the ownership of a community music workshop is shared by all those taking part (Higgins, 2012). Equally, Aigen (2005) argues that creating a performance or product such as a recording can be a natural impulse when engaging in music and a worthy focus in music therapy (pp. 116-117).

In a recent Canadian study, 16 older adults both with and without cognitive impairments took part in group singing sessions and reported benefits in mood and energy and a sense of community, among other improvements (Clements-Cortés, 2014). The facilitators were music therapists, and their presence was considered important in the study. The identified advantages of having music therapists involved included their facilitation of 
the time before and after music-making, individual follow-up of choir members, choosing music with therapeutic intention, skills to help any participants who became confused, and a focus on 'the beauty of making music' rather than perfecting the end product (ClementsCortés, 2014, p. 101).

In reviewing some of the literature in this area, I have found that distinctions between community music and community music therapy can sometimes unfairly characterise community musicians as being product-driven and less responsive to participants. Aigen (2012) suggests a continuum of traditional music therapy, community music therapy, therapeutic community music, and community music. He acknowledges that specific examples of practice may be hard to precisely locate on this scale, and it could be argued that which label one chooses is ultimately of no great consequence, except where it relates to gaining funding or legitimacy.

Nonetheless, from reading the literature I had some ideas of ways in which drawing on the community music therapy framework and principles could improve my practice. I thought that being aware of the debates surrounding areas of practice, such as the use of performance, may help me to critique my work, be aware of my limitations in this setting and see where my focus would be best placed. I also wanted to keep the principles of client ownership in mind, to ensure that I was not prioritising the musical product over the process; this was a potential pitfall in my context as it was appealing to be seen, or heard, to be successful by the care home staff. I viewed the facility as its own community, and I hoped that community music therapy could help me to keep a wider perspective on how the community environment was impacting individuals, and vice versa.

\subsection{Community music therapy principles}

Community music therapy can be difficult to define, in part because it is a relatively recent movement and also because it encourages diversity in approach relative to individual context (Pavlicevic \& Ansdell, 2004). However, important qualities or principles which characterise community music therapy work are shared between different approaches. The key principles of community music therapy are often summarised using the acronym PREPARE, which was introduced by Stige and Aarø (2012). PREPARE stands for Participatory, Resource-oriented, Ecological, Performative, Activist, Reflective, and Ethicsdriven (Stige \& Aarø, 2012, p. 18). 
- Participatory refers to how participation is valued and supported, and the opportunities provided for individual and social participation.

- Resource-oriented refers to the use of personal strengths and available social, cultural and material resources.

- Ecological highlights the influence between individuals and their environment, and how each can affect the other.

- Performative refers to music performances and also to the ability of participants to perform relationships and identities through music (Steele, 2016).

- The Activist principle acknowledges that an individual's problems are related to limitations in society, and aims to change this in some way. It also recognises how the attitudes implicit in the music therapy work contribute to wider social change.

- Reflective practice should include ongoing questioning of the work, individually and with others, to gain better understanding.

- Ethics-driven recognises the values behind the work, and how it is based in human rights.

Stige and Aarø (2012) suggest some ways in which music encourages community. They consider music to be intrinsically social, something which 'pulls people into a social space' where they can interact through sound and movement (p. 115). They suggest that 'Communal musicking is an eminent vehicle for collective action, collaboration, and group cohesion' (p. 127). The word 'musicking' here comes from Small (1998), who proposed it should be used to refer to taking part in music in any capacity. This includes listening, dancing, and composing, as well as playing. Small also suggests that musicking creates relationships between all those taking part, positioning music as relational by its very nature. One of the definitions of community music therapy suggested by Stige is 'situated health musicking in a community' (Stige, 2012, p. 45).

Ansdell and Stige (2016) present community music therapy as a movement, reflecting how it has developed in multiple areas and functioned as both a critique of established methods and inspiration for new practice and theory. Community music therapy encourages questioning of who we are as music therapists and what the scope of our role and work is, which is the process I was going through as a music therapy student in a new environment. Community music therapy principles can be considered within a particular context to develop new perspectives and challenge assumptions, with an acknowledgement of how the wider 
social, cultural and institutional environment impacts on the music making (Pavlicevic, 2012).

As noted above, around half of people entering residential care have a diagnosis of dementia, and in this area person-centred care, pioneered by Kitwood (1997), is now a widely accepted and important approach (Klopper, 2017). Person-centred care is one of the guiding principles of the New Zealand Framework for Dementia Care (Ministry of Health, 2013), and is becoming a key part of healthcare practice internationally (McCormack \& McCance, 2017). It seems that community music therapy has many values and principles in common with a person-centred approach. Inclusion, or 'having a distinct place in the shared life of a group' (Kitwood, 1997, p. 83) is considered to be one of the key needs for people with dementia. Some of the other needs identified by Kitwood, including comfort and identity, can also be supported by community music therapy.

Many of the types of positive interaction outlined by Kitwood can be contained in community music therapy. In particular recognition, negotiation and collaboration are all aims of a participatory approach. Play and 'timalation', primarily sensory interaction, can also be encouraged (Kitwood, 1997, p. 90). Taking an ecological approach and encouraging caregivers to be involved can enable them to play, create, and collaborate with the person with dementia. This can also help them to see the personhood of someone with severe illness. A resource-oriented approach such as community music therapy encourages creation and giving, both considered important in person-centred care, as the person's individual skills and experience are acknowledged and encouraged. This all relates to the activist nature of both community music therapy and person-centred care which aims to influence and change the nature of the environment and the care given.

There is a scarcity of research into the use of community music therapy with older adults, and in particular with people with dementia, despite the fact that many people with dementia will move into a residential care home or specialist dementia unit as the condition progresses. A care home is a unique environment: part workplace, part home, it is a place that very few of its residents will have been familiar with before coming to live there. It is a community, but it lacks many of the elements that traditionally bind communities together; although it is a community based on locality (Stige, 2004), residents generally come to live there out of necessity, not preference. I was interested to find out whether, and how, I could incorporate some of the principles of community music therapy into my work with this client 
group. However, I wanted to remain open to all possibilities, so I began with the initial research question 'what strategies are effective for engaging large groups of older adults in music sessions?' 


\section{Methodology}

My theoretical framework is interpretivist, and I decided to investigate my question using action research. An interpretivist framework is consistent with community music therapy theory, as it considers people within their wider setting and takes the view that a person cannot be understood separately from their context. It can be said that 'The goal of interpretive inquiry is the interpretation of the interpretations people give to their own actions and the actions of others', and I was intending to research (interpret) my own interpretations (practice notes) in order to improve my practice (Smith, 2008, p. 460). Interpretivism also suits the personal focus of my research, as I was investigating my 'direct lived experience', rather than attempting to make wider generalisations (Hurworth, 2005, p. 210).

\section{$\underline{3.1 \text { Action research }}$}

Action research is an orientation towards the research process which focuses on realworld change (Stige \& McFerran, 2016). Many different methodologies can be used in action research because it is primarily an attitude towards research, and the methods necessary will vary according to the research goals in order to ensure the results have relevance. Action research is well suited to my research question, as I wanted to investigate and improve my own practice, and within this method action undertaken in context is a way to both generate and test new knowledge and practices (Greenwood \& Levin, 2007). The application of findings is encouraged throughout the process.

Action research has an activist component which is more or less emphasized depending on the concerns of the participants and the research question developed. I have used pragmatic action research, which generally focuses on finding a solution for the problem under investigation rather than looking at wider social issues (Greenwood \& Levin, 2007, pp. 133-134). This was to ensure the scope of the research remained manageable and clearly focused on the research question.

My main data source was my practice notes, including reflections and ideas for improvement, from my time on placement. I also drew on the community music therapy literature in order to develop my practice. Within each of my three action cycles I first collected data for a period of around six weeks, then used thematic analysis to examine this 
data and decide on the emerging themes. Based on these themes I generated actions I could take into the next cycle to improve my practice.

\subsection{Thematic analysis}

In line with the suggestions made by Nowell, Norris, White, and Moules (2017), I have described the thematic analysis and decision making process so that readers can make an informed judgement on the credibility of the conclusions reached.

I followed the six-step process initially outlined by Braun and Clarke (2006), and expanded upon more recently by Terry, Hayfield, Clarke, and Braun (2017) to analyse the data. I felt that this method would fit my research as it is clear and accessible to new researchers, designed for qualitative research, suits written data, and aims to ensure 'rigorous and systematic engagements with data' (Terry et al., 2017, p. 34). This approach is also widely used within interpretivist music therapy research (Hoskyns, 2016). This process involves the researcher familiarising themselves with the data, generating initial codes based on interesting features of the data, collating codes into potential themes, reviewing themes for coherence and distinction from one another, defining and naming themes, and producing the final report with selected extracts.

I decided to analyse all group sessions together, rather than separate the different groups. This was for several reasons: I was interested in the common factor between the groups, namely myself and my practice, and I felt that the themes and resulting actions would have greater validity if they were supported by data from a range of sources. I wanted to investigate my group practice as a whole, so I decided to focus my energy on reflecting the entire data set in the themes rather than concentrating on each individual group.

However, I was aware that different groups may require different approaches, and that insights relating to one group would not necessarily be relevant for another. I remained open to the idea of investigating the groups separately, and to generating different actions for the groups. Within my raw data I kept the headings marking which group the notes related to, so that I could see which groups were represented most heavily in certain themes, so that if this was relevant it could be factored into the analysis.

Each cycle uses a minimum of five weeks of data for the thematic analysis, to try to ensure that longer term trends are present in the themes rather than unusual or isolated events. 
This means that notes from around 25 group sessions have been analysed in each cycle. Of these around half were sessions held in the secure dementia unit. My first cycle of data gathering started on the fourth week of my placement, after I had settled in, become used to the facility and started to build a rapport with many of the residents I would be seeing regularly. I also made some quite significant changes to my schedule at this point, so I felt that if I used data from earlier in my placement it would not be as valid, as the sessions were quite different. Further adjustments were made to the schedule throughout my placement, but these did not significantly affect the nature of the groups in the same way.

I attempted to keep a reflective diary, in order to ensure reflexivity in my practice. I found this difficult to maintain however, and I realised that I was already including reflective thoughts and ideas in my main notes so the diary felt redundant. The notes I kept on placement were not shared with staff, as I wrote separate reviews for others to read, so I was free to include my thoughts, questions and ideas for future sessions. I found it more useful to include my reflections in my notes rather than in a separate space, as I would look back in my notes when planning sessions and this would ensure my thoughts were influencing my practice, more so than if I kept a reflective diary. For me, this method fit better with my style of practice. Therefore these thoughts are included in my analysis via my notes. For example in this extract:

I tried giving out instruments during a song again this week, but I don't think this is very effective as residents may be confused as to whether I'm offering them an instrument or playing it myself. Offering them instruments out of the box seems to work better.

I used the specialist software NVivo for my thematic analysis; Appendix 2 shows an example of coding within NVivo. Appendix 3 provides further explanatory detail of the data analysis process in each cycle.

\section{$\underline{3.3 \text { Ethics statement }}$}

This project was reviewed and approved by the New Zealand School of Music Postgraduate Committee. As I have undertaken my research as part of the Master of Music Therapy degree, the project is covered under the ethical approval gained from the university ethics committee for the programme (Ethics Approval: 22131). Practitioner action research is 
covered by this approval. The music therapy projects have been judged to be low risk and, consequently, are not separately reviewed by any Human Ethics Committees. Appendix 1 shows the information sheet and consent form provided for the facility.

As well as following Victoria University of Wellington's human ethics policy I have followed the Music Therapy New Zealand Code of Ethics in both my practice and research (Music Therapy New Zealand, 2012). I have also been guided by my research supervisor at the university. I liaised with the pastoral care advisor at my placement facility and I have spoken to a Māori learning advisor at the university.

As I have investigated my own practice, no human subjects were involved and the ethical risks are low. I have included a vignette describing a typical group session, focusing on my experience as a facilitator. In this vignette pseudonyms have been used for both residents and staff, and no information is included which may identify any resident or staff member to others outside the facility. Pseudonyms are also used in all data extracts provided. 


\section{$\underline{\text { 4. Findings }}$}

I undertook three cycles of action and learning which each produced three major themes. I have presented each of these in turn along with the mind maps I created, which demonstrate how I arranged the codes into themes and the connections between themes. Aspects of each theme are illustrated with quotes from my practice notes.

\section{$\underline{4.1 \text { Cycle } 1}$}

My question for cycle one was 'what strategies are effective for engaging large groups of older adults in music sessions?' I wanted to understand more about what was helpful or valuable in sessions and to be open to various possibilities. My themes in cycle one were 'expect the unexpected', 'moments of connection' and 'enabling communication'. These reflect how I encouraged participation in sessions by enabling communication through a variety of means and facilitating moments of connection between participants, and how residents engaged in ways which were unexpected and often creative. These themes focus on my skills and interactions with group members, rather than having a wider community perspective. I feel this reflects my interests at the time as a student music therapist establishing myself in a new environment. 
Figure 1: Mind map of codes from Cycle 1

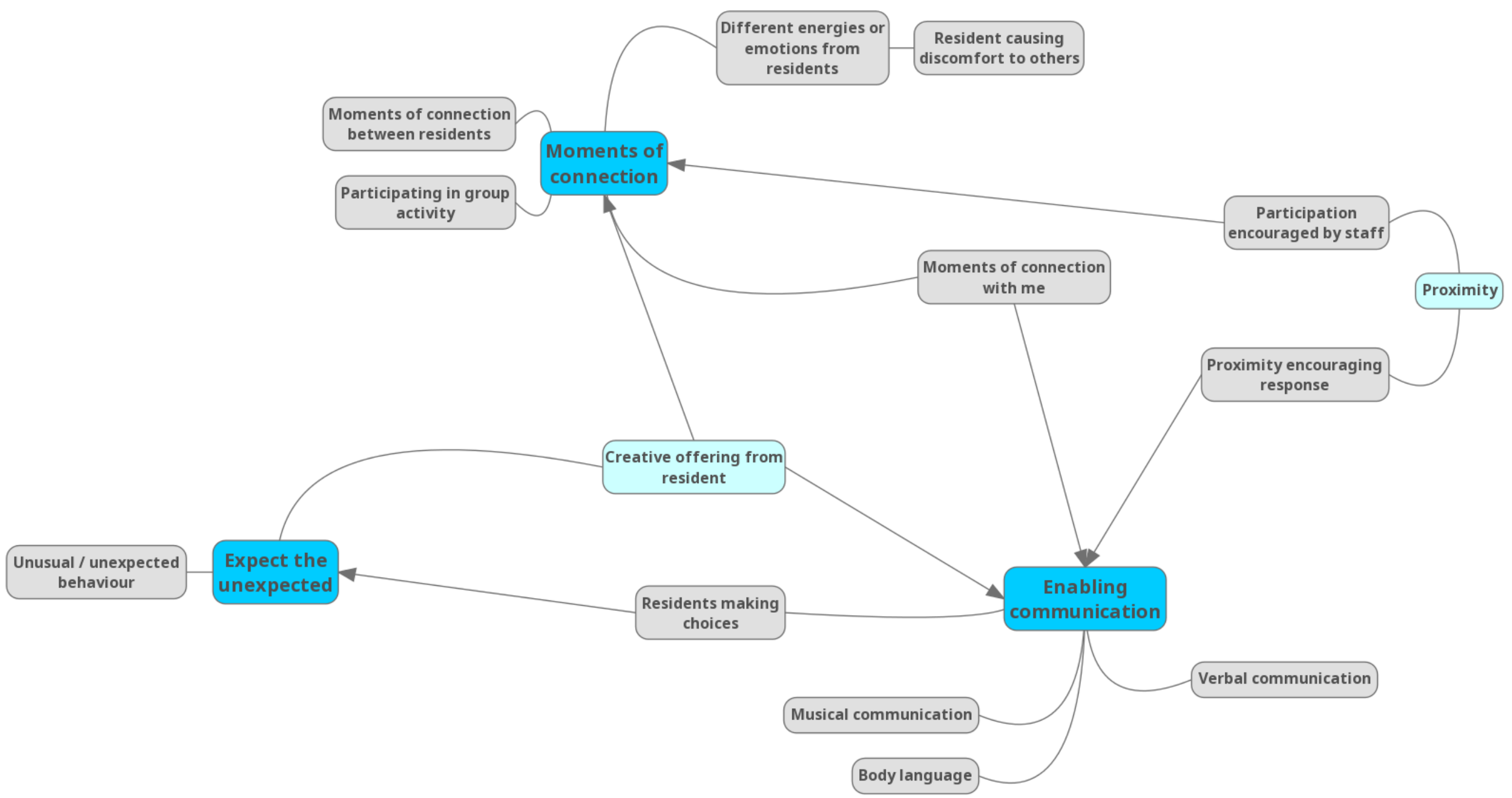




\section{Theme 1: Expect the unexpected}

\section{I should expect the unexpected and allow space for residents to participate in the session in a variety of different ways.}

This theme was based on my finding that I experienced a number of moments where a resident displayed behaviour which I felt, or was told, was unusual for them, or a resident did something unexpected based on what I knew of them.

James was smiling at me, and when I offered him the tambourine he moved his hand straight away to hold it and tried tapping it. This is the most intentional I have seen him in interacting with music.

I was surprised by James' independent playing in this moment as I had never seen him use instruments in an intentional way before. Considering that I felt these occurrences were unusual, they occurred surprisingly often in my notes. These moments felt important as they disrupted my pre-conceived narrative of the resident and what I thought I could expect from them, which in many cases I was not aware I had formed until it was challenged.

One of the principles of community music therapy is that it is a participatory approach: Stige and Aarø (2012) write that 'Community music therapy practices build on the idea of partnership and value the input and contributions of all participants' (p. 148). At times unexpected moments would contain a creative offering from the resident, and this reminded me that it is important to allow space in the session for residents to take it in a different direction than I had planned.

Laura came in part way through and at one point was singing quietly with me, singing her own words and tune but in a way that harmonised with me.

The ability for residents to participate in the session as much as possible, and for their ways of participating to be maximised, is crucial. However, in encouraging participation it is important to recognise that the person may need extra support. Structure and direction are still required in the session to provide a framework which supports residents to participate; the challenge is to ensure that this support is flexible enough to allow for unexpected occurrences and improvisatory offerings. 


\section{Theme 2: Moments of connection}

Music sessions can provide opportunities for moments of connection, both for residents to connect with each other and for residents to connect with others including staff.

The creative offerings from residents also often led to moments of connection. This was the central theme from cycle one, as I think that building community in this context can be best pursued by creating moments of connection between participants.

\section{Mary and Pat were sat next to each other and I felt that Pat's singing} encouraged Mary to join in as well ... At one point they were singing together in between the main lines of ' $O$ when the saints', and they were looking at each other at times so I feel that they were aware of each other. They sang 'Pokarekare ana' strongly in harmony.

This is similar to the concept of 'bonding and bridging' described by Putnam (2000) and used by Stige and Aarø (2012, pp. 214-217). Bonding is used to refer to connecting people within a largely similar community, and could be used to describe connections made between residents such as the connection between Mary and Pat above. Bridging refers to connecting people from different communities, such as the connections made between residents and staff. Bonding and bridging are both forms of 'social capital'; social connections and networks which bring value to individuals and the community. Putnam (2000) suggests mutual support, cooperation and trust as potential positive effects of social capital (p. 22).

Sarah was mostly walking around, but was interested in the music box and explored the instruments there a couple of times. At one point a care worker persuaded her to sit down and hold the tambourine whilst the care worker played it, which she seemed to enjoy, smiling.

Bonding and bridging can be increased by participating in group activities which encourage social connections, particularly when participants have autonomy over how they participate. Procter (2004) extends the idea of social capital to 'musical capital': a form of social capital which also "carries opportunities for aesthetic self-realisation and selfexperience' (p. 228). He suggests that the music therapist's role is to provide opportunities to develop a healthy relationship with music within communities.

However, I also encountered problems in large groups where residents experiencing very different emotions or energy levels could cause discomfort to each other. In some ways 
this was difficult because the conflict resolution or learning to co-exist socially which we might hope for was not possible for some residents. Some had advanced dementia or other problems which made it difficult for them to regulate their emotions and understand the actions of others. Again, residents' health challenges must be taken into account when considering how best to support them, and collaboration with staff is important in order to be aware of residents' health and abilities.

\section{Theme 3: Enabling communication}

\section{Enabling communication through a variety of means, including music, provides more opportunities for residents to participate in the session.}

Enabling communication was extremely important to encourage moments of connection between residents and myself, and to enable residents to make choices which could lead to creative or unexpected occurrences. I found that communication based on body language and based in music often overlapped in my sessions:

Michael took the tambourine I offered him and played for every song; he kept time well, looked at me often and raised his eyebrows, and ended songs together with me.

My offering of the tambourine was by gesture as well as verbally, and my music encouraged Michael as I ensured the tempo was suitable for him to play along and emphasised the pulse. Michael's body language of raising his eyebrows appeared to show that he felt connected to me, and in ending songs together we confirmed this connection.

There was rarely a significant verbal component to these interactions, suggesting that body language and music were enabling communication where verbal communication was ineffective. I also found that proximity was important for enabling communication, as being near to a resident often seemed to encourage them to respond.

Amy was sitting in a different part of the lounge; she didn't come over but when I came over to sing near her she acknowledged me with her facial expression.

This highlighted how helpful it was to have staff members in sessions, as they were able to encourage residents individually to participate and could spend more time with an individual resident. 


\section{Actions}

Based on these themes I developed actions to take in the next cycle, all of which were focused on increasing the opportunities for moments of connection. I wanted to ensure that sessions provided a strong framework within which residents were supported to participate as they wished, creating an enabling environment rather than a disabling environment. The literature suggests that recreative techniques, singing or playing music which is already composed, can facilitate communication, increase expression of feeling and stimulate reminiscence and interaction (Clements-Cortés, 2016). Lesta and Petocz (2006) investigated small group singing with people living with dementia and felt that the structured participation of using familiar songs may have provided the best sense of community the participants were able to experience.

I found that evidence of participation by some or all residents in group activities was represented evenly throughout my notes, which encouraged me that session activities were providing suitable opportunities for participation. I continued to use the structure of familiar songs, group activities and playing instruments as the backbone of the session, but I aimed to provide more flexibility to encourage creative, communicative moments of connection. My actions were:

- I can extend the instrumental gaps in songs, providing a space to offer something new which is still held within the structure of the song. In the example with Laura above, I could have played an instrumental verse, perhaps humming or singing the tune to 'la', to encourage her creativity.

- I can continue to provide residents with new opportunities to participate, such as using new instruments or joining in with a new group activity, as different situations could prompt residents to act in different ways. In doing this I will attempt to balance adapting activities to suit residents' needs, and not assuming that residents will always act in typical ways. In the example above James responded to the offer of the tambourine, and whilst I can continue to offer him the tambourine at times I can also offer him other instruments, as he may respond to these differently.

- I can be more exaggerated and intentional in my body language, to encourage communication, and use proximity in a more intentional way, such as making sure to be near to a resident if I am specifically inviting them to participate. In the 
example with Amy, I could have responded to her acknowledgement with a more exaggerated facial expression and perhaps a gesture, to reassure her that I had recognised the connection we made. 


\section{$\underline{4.2 \text { Cycle } 2}$}

My question for cycle two was 'how can I facilitate moments of connection between residents, and between residents and staff or visitors?' In cycle two I was able to broaden my focus to consider interactions between residents, visitors and staff to a greater degree, as I became more able to engage residents in sessions based on my findings and actions from cycle one. I was also starting to build relationships with staff and I was able to consult them about my schedule, which resulted in some changes so that music sessions were not disrupting other tasks. This also meant that staff members were able to participate in sessions more often.

My themes were 'disrupting and trying something new', 'performing identities and rituals' and 'inclusion and participation'. I facilitated moments of connection by introducing new activities which disrupted typical patterns of behaviour, supporting participants to perform identities and social rituals, and facilitating inclusion and participation in musicing.

Although it is common in the music therapy literature to use Small's (1998) interpretation of the word 'musicking' when describing music-making, I have instead decided to use the related 'musicing', as suggested by Elliott (1995) and used by Ansdell (2004), and more recently updated by Elliott and Silverman (2015). Musicking is a broad term according to Small, who defines it as 'to take part, in any capacity, in a musical performance', including setting up instruments, cleaning up after performances and taking tickets (Small, 1998, p. 9). Musicing is more focused, meaning 'all forms of music making ... in all types of cultural situations', including playing, arranging, recording, moving and listening (Elliott \& Silverman, 2015, p. 16). I feel this term is more appropriate for my context, where participation and music-making was the focus of our sessions. 
Figure 2: Mind map of codes from Cycle 2

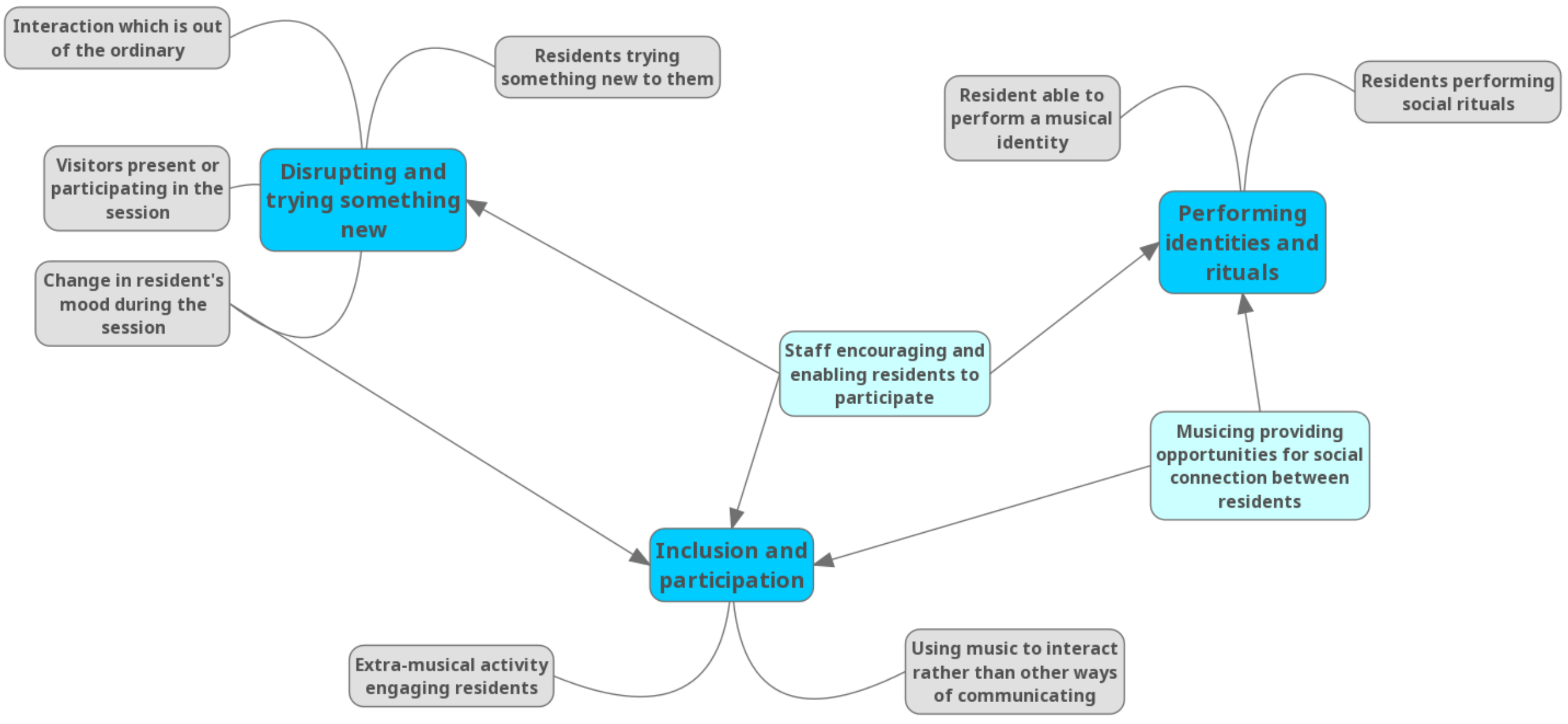




\section{Theme 1: Disrupting and trying something new}

\section{Musicing can disrupt usual patterns of behaviour and interaction, and encourage residents, staff and visitors to resource themselves in new ways.}

I found that residents were trying things which were new to them in music sessions, sometimes as a result of direct encouragement from me or a staff member or visitor, and sometimes through their own initiative. This might have been choosing to sit with others in the session for the first time, or playing an instrument they had not tried before.

Paul showed the most engagement in a session so far today; he was unsure about the tambourine at first but agreed to try after I encouraged him and demonstrated how to play. He played for a little while at the beginning then the end of the session.

For some residents with dementia an experience might feel new to them even if it has occurred before, so the ability for residents to be supported to try things which feel new may be particularly important. Alongside this, I noticed many times when a resident's behaviour changed which seemed to indicate that their mood had changed during the session.

\section{Rachel was facing the wall at first for several minutes and then started} walking around the room, frowning and looking down. Later on she came to sit in the circle, unprompted, and was looking up at us and smiling. She held a scarf with Emily and stayed for the rest of the session, over 20 minutes, smiling most of the time.

In these instances residents seemed to be able to use musicing to change their behaviour and perhaps also their mood. Although I generally tried to follow Pavlicevic's (2003) suggestion of starting by playing in a way which reflected the feel of the group, and then gradually changing the energy, this was not always possible when there were very different moods present in the group. It was also challenging musically to balance reflecting feelings in the group with providing a strong and engaging start to the session. However, at times this might have benefitted residents, as they were able to join in with the music and affect their mood:

Mark was enthusiastic in today's session, playing fast beats on the tambourine and often singing along ... this was despite saying [at the start of the session] he was still feeling unwell from his cold. 
I also noted some interactions which were 'out of the ordinary', similar to the 'unexpected' moments from cycle one, and many of these were playful and disrupted the usual staff-resident dynamic.

Daisy played the tambourine as well as the maraca and put it on her head like a hat, making her laugh and a caregiver and I laugh as well.

In this moment Daisy shared a joke and experienced being an entertainer. These interactions allowed residents and staff to build deeper relationships, and for residents to experience different roles and aspects of their identity. From cycle one I aimed to provide more opportunities for participation and interaction in a variety of ways, which may have allowed more space for these moments to occur.

Visitors were not present in sessions very often, and some appeared more comfortable to join in with the session than others. At times visitors and residents were able to make music together, providing them with a different way of interacting:

Nick sang along to several songs today in a strong voice with some vibrato, perhaps encouraged by his wife who was also singing. He smiled when using the parachute and laughed when they played with a scarf together.

Sometimes visitors were present but did not participate, which encouraged me to think of ways in which I could make sessions more accessible in order to include them in the future.

\section{Theme 2: Performing identities and rituals}

\section{Residents can be provided with opportunities and resources to develop and perform musical identities and social rituals.}

Residents were able to enact both long-standing musical identities, such as being a guitar player or a drummer, and to develop new ones, for example by consistently choosing an instrument to play and making it 'theirs'. Due to the large group size residents were in some ways 'performing' these identities, as they were being witnessed and confirmed by the rest of the group (Steele, 2016). A common way this occurred was through residents requesting or starting songs: 
Bethany sang 'come over here nurse and hold my hand', with minimal accompaniment from me, and 'Kiss me goodnight Sgt Major' which several other residents joined in with.

In this moment several residents joined in with the song Bethany started, providing a musical connection between them and leading to a discussion about wartime songs. This was a way to share musical preferences with the group and to affirm a musical identity tied to the time and place these songs come from. It was also an opportunity for participants to reveal something about themselves to others (Stige, Ansdell, Elefant, \& Pavlicevic, 2010).

In several instances staff involvement was crucial to enable residents to access these musical identities, such as when staff were able to dance with residents or could suggest a song or instrument which they knew the resident had a connection to.

Poppy suggested several songs which the residents might enjoy, one of which was 'How Great Thou Art'. Jo particularly enjoyed this song, singing it through with a lot of energy, and Paul played more loudly on the tambourine.

This was particularly helpful when residents were not able to talk or easily make choices, or when residents found it difficult to remember previous musical experiences. This highlighted to me the importance of finding ways to inform staff about my work, as otherwise this information might be lost over time, and enabling staff to participate in sessions.

Residents were also able to perform social rituals, which provide structured ways of participating in community. These included singing 'Good Morning' and 'Hello', shaking hands at the beginning of the session, and applause after songs or at the end of the session. Stige and Aarø (2012) suggest that 'shared attention and increased emotional energy' can result from these 'interaction rituals' (p. 134).

Began by singing 'Good Morning' and Emily [a staff member] shook hands with residents, most of whom made eye contact and responded to her through facial expression or verbally.

These rituals can confirm identity as a group member. Some, such as shaking hands or applause, are also established cultural practices which can be a form of communication. 


\section{Theme 3: Inclusion and participation}

\section{Musicing provides ways for diverse individuals to participate and be included in the community.}

I found many examples of musicing providing opportunities for social connection between residents. In each session residents had diverse needs and abilities, which often made social connection between them more difficult. For example, in each group some residents could hold a conversation with others and some could not. In this moment, two residents who had very different cognitive abilities connected through music:

Claire and Jean stood close to me and seemed interested in the ukulele. I started playing and they both moved from side to side in time with the music, looking at each other. I started singing 'Good Morning' and they both started singing with me; Claire sang in her own style and Jean sang the words of the song.

Both styles of singing could be contained within the music, connecting the residents in a shared moment. Some residents chose to interact through music rather than communicating in other ways, as in this moment:

He kept his eyes closed most of the time at first, but started playing the tambourine and played for several minutes by tapping it lightly. At the end of the session he picked up the maraca that was on the table and played a clear rhythm on beats 3 and 1 of 'Now is the hour', smiling but still with his eyes closed.

Here the resident chose to play instruments but did not make eye contact or sing, which he had done in other sessions.

Including a variety of different elements in sessions, such as a parachute or blowing bubbles, also seemed to provide opportunities for residents to participate in different ways.

Kirsty stayed in the room for the whole session today, even coming into the middle to use the parachute which is unusual for her. She sang in harmony to a few songs and seemed to be in a positive mood.

Collaborating with staff was once again important in order to be able to use these different activities.

This finding felt like an extension of my 'moments of connection' theme from cycle one. In Groups in Music, Pavlicevic (2003) writes: 'Flowing together as persons is about 
musicking in the sense that our acts of being and engaging with one another musick us towards one another' (p. 237). I found that the flexibility of the music and ability of residents to participate in a variety of ways provided an inclusive model of community.

\section{Actions}

As cycle three would mark my final weeks spent on placement at my facility, my actions were focused on ways for music-making to continue beyond my time at the home. A commitment to sustainability has been proposed as an important value in music therapy generally and community music therapy in particular (Bolger \& McFerran, 2013), as part of a commitment to ethics-driven practice (McFerran \& Rickson, 2014). Sustainability has been defined as 'prioritising and planning for the ongoing impact of a program beyond the life of the music therapist's direct involvement' (Bolger \& McFerran, 2013). I hoped that some of the benefits of musicing which I had identified could persist if I encouraged staff and visitors to use the resources they had to continue music-making.

Bolger and McFerran suggest that collaboration, time and realistic expectations are key principles when establishing sustainable practice. I had been at my placement for over six months by this point, and in that time I had been able to develop a rapport with many staff members and had started to understand some of the pressures and challenges they faced. I was also able to collaborate more often with staff and visitors over time, which gave me an idea of what realistic expectations might be for including more music in the life of the home. My actions were:

- I can include elements in sessions which staff and visitors can use.

- Use recorded music owned by the facility in sessions, to model how this could be used by others. None of the staff I have worked with have felt confident to play instruments with the residents, but recorded music is already used as background entertainment so using it in a more intentional way seems realistic.

- Make notes on activities and songs which are popular and can be used by others. These can be added to pre-existing playlists and incorporated into the activities programme.

- Ask residents what aspects of music sessions they value and want to continue, either within sessions where appropriate or potentially in a residents' meeting or other forum. 
- I can support staff and visitors to resource themselves by being more intentional in the ways I invite them into the session.

○ Suggest a clear role or task to staff and visitors, e.g. 'would you like to help Martha to play the tambourine?' or 'Peggy might like to dance with you today'. Suggesting a role for them might help them to participate if they are unsure about how they can join in.

- Some people may feel more comfortable with non-musical activities such as blowing bubbles or dancing with scarves. I can bring these activities to sessions more regularly and suggest that staff or visitors use them.

- I can work towards finding ways for information on residents' musical identities to be recorded and shared with staff.

- Explore potential for some music therapy notes to be included in residents' files.

○ Write a short blurb on residents' musical identities and preferences which can be kept in the recreation office. 


\section{$\underline{4.3 \text { Cycle } 3}$}

My question for cycle three was 'how can I encourage and support staff and visitors to continue music-making after I leave the facility?' My findings in cycle two had given me ideas of ways that music sessions could be adapted to be more accessible and inclusive, and to include elements which might be helpful in the future for staff. I knew from the literature that taking part in music therapy can affect how caregivers interact with residents, and I was hopeful that through participating in sessions staff might have experienced different ways of connecting with residents.

My themes were 'traversing boundaries', 'choices and self-determination' and 'drawing people together'. I encouraged staff and visitors to continue music-making by facilitating shared moments that traversed role boundaries, maintaining a flexible environment that promoted autonomy and self-determination, and enabling staff to experience the power of music to draw them into a shared physical, cognitive and emotional space with residents. 
Figure 3: Mind map of codes from Cycle 3

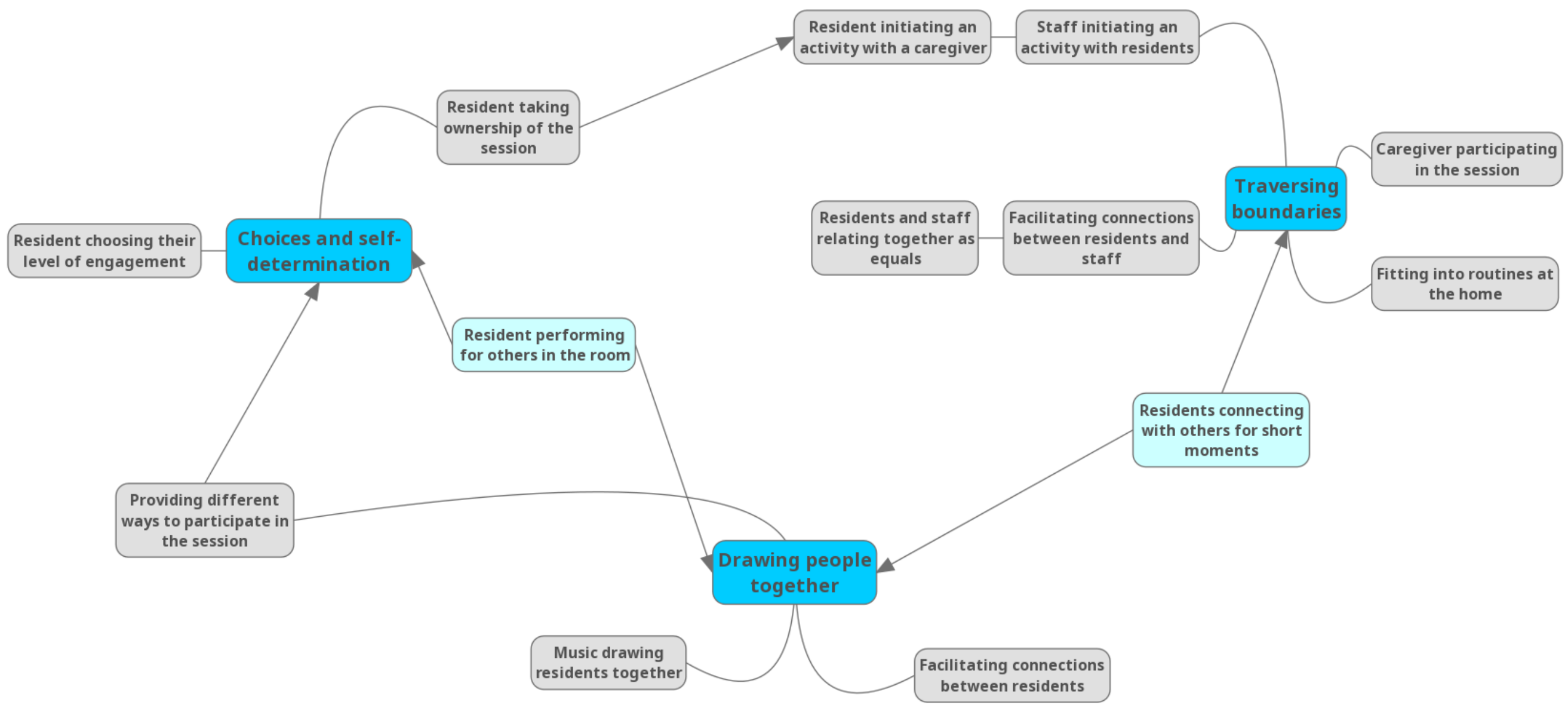




\section{Theme 1: Traversing boundaries}

\section{Shared moments in music can traverse the boundaries between the roles of 'staff' and 'resident', allowing for connections on a more equal level.}

'Traversing boundaries' related to the way in which session participants were able to connect across the boundaries of 'residents' and 'staff'. One of my actions from cycle two was to be more intentional in the ways I invited staff into the sessions, by suggesting a clear role or task for them and increasing the availability of non-musical activities. I found many instances of staff, particularly caregivers, participating in sessions, without needing to be specifically invited in. Often this was through playing instruments or helping residents to play, but I did find the multi-sensory activities increased opportunities for staff to participate.

One of the caregivers walking past stopped to watch us with the parachute. She suggested going underneath, and hid under the parachute, waving her hand through the hole in the middle. Some residents smiled or laughed and it was a playful moment.

This caregiver was not able to participate throughout the whole session, but she was able to connect with residents in a fun way during this moment. Fitting into routines at the home and being flexible allowed caregivers to participate more often in sessions. As noted by Tuckett et al. (2015) the timing of music therapy groups can significantly impact caregivers' ability to complete their tasks. It was important to make sure that sessions did not obstruct residents having their necessary cares performed or delay meal times, to ensure that music therapy was not increasing the burden on caregivers. This also meant that caregivers were more likely to be free to participate in sessions.

I found that some interactions between staff and residents seemed to temporarily remove the barriers of those different roles and allow for a connection on an equal level. Moments of residents and staff dancing together often had this feeling, as did this brief moment:

Susan and a caregiver were looking at each other and playing long tremolos at the end of songs, laughing.

Susan and the caregiver were equally involved in the activity and both gained enjoyment from their shared connection. Their playing together arose spontaneously rather than being directed, increasing the feeling of equality. Pavlicevic (2010) discusses this feature of 
important moments in group work, saying 'the (socially assigned) identities and roles of therapist and clients seemed to meld: all became people doing "magic" music' (p. 100). A similar levelling effect seemed to happen between staff and residents at my facility.

I found instances of staff initiating activities with residents, such as playing instruments together, and conversely residents initiating an activity with a staff member. This seemed particularly important as it had been difficult to engage staff in sessions at the start of my placement, but now they were actively participating and engaging with residents without any prompting. I found fewer instances of residents initiating activities with staff, but these moments most clearly seemed to demonstrate residents seeking connection with staff, as in this example:

Amy was asleep at first, then woke up and left to go to the toilet. She came back later and sat in a different chair to usual, next to one of the caregivers who was playing the bells. She also played the bells and bounced her feet with a lot of energy, smiling and looking around. She then started chatting to the caregiver who was with her.

This resident would always request to play the bells, so possibly the fact that a caregiver was also playing the bells inspired her to move from her usual spot, where she spent most of her time watching the door to her room, and play together. I found most instances of these connections between residents and staff in sessions in the dementia unit; these were the sessions which happened most regularly, which may explain this difference.

\section{Theme 2: Choices and self-determination}

\section{Large open group sessions still have flexibility for residents to make choices and experience self-determination.}

Residents initiating activities with staff also seemed to fit into a wider theme of residents making choices and beyond that having a level of self-determination. In particular one of my main codes for this theme was 'residents taking ownership of the session'.

As we started singing 'Hello' Poppy was singing 'Johnny's so long at the fair', which we joined in with and Poppy said "do you know it?" and seemed pleased. 
Residents were sometimes more directive in sessions in this way, rather than waiting for invitations to make choices. I felt that this suggested they were comfortable in sessions, and felt confident to try different ideas. At other times residents took a session in an unexpected direction:

I asked for requests during the session and Emily suggested that Richard might have an idea. I spoke to him and he said that we could do a Christmas song “just for a bit of fun”. I suggested 'Jingle Bells' as earlier Emily had been commenting on how the bells sounded like sleigh bells. Many residents sang along, particularly with the chorus.

I was surprised by the suggestion of Jingle Bells as this session did not take place near to Christmas. This is similar to Stige's concept of 'adventurous participation', which contributes something new to the situation, moving beyond the requirements of conventional participation (Stige, 2010, p. 131).

I also noted occasions when residents were performing for others in the room; from simply singing happy birthday with the group to starting a song solo. Sometimes the performances were not just musical:

Paul agreed to take the tambourine I offered him and played a little before putting it on his head; he did this a few times and seemed to enjoy the attention he got from other residents and staff, smiling and laughing a little as he looked around.

This indicated Paul's awareness of others in the room and created an opportunity for nonverbal communication and playful connection between Paul and other residents and staff, again traversing this divide of roles.

I noticed that music sessions allowed residents to control their level of engagement and activity. One benefit of having open sessions was that residents who were more mobile could leave and return as they wished:

Mark was in the session at first ... After a few songs he left, then later he stood near to me when I was playing 'I get by with a little help from my friends' on the piano, and I wondered if he enjoyed this song.

In a more strictly boundaried, closed session Mark might not have been able to join me for this song, but as I was playing in the open lounge area he could hear the music and choose 
whether and when to participate. Some residents preferred to stay near the doorway or around the corner from the area where the session was taking place, but still participated in the session activities. This relates to the metaphor of the 'ripple effect' (Pavlicevic \& Ansdell, 2004, p. 16), where the music expands outwards from the specific session or interaction into the wider environment of the care home.

\section{Theme 3: Drawing people together}

Music draws people together into shared physical, cognitive and emotional space.

As in previous cycles a strong theme was music providing opportunities for connection by drawing people together physically, cognitively and emotionally. This facilitated connections between residents, and between residents and staff.

When I arrived I waved to Jennifer who was sitting in the corridor, and she waved me over. I went to say hello and asked if she wanted to join in the music in the lounge, and she said yes and stood up. As we walked I began singing 'Savalivali' and she joined in with me, singing strongly and holding my arm. We finished the song and Jennifer sat down in the lounge. A caregiver clapped and said "thank you for that Jennifer!"

This supported the assertion by Stige and Aarø (2012) that music is intrinsically social, and brings people into a social space where interaction is then possible. One of the potential benefits of large group sessions was that residents who spent most of their time asleep could be present in this social space and participate and connect with others when they were awake. I also felt sometimes that the energy of a group session encouraged residents who were tired or had low energy to participate. This example was typical of such interactions:

Terry was asleep for most of the session, however he woke up towards the end of the session and held hands with Emily. They swung hands in time to the music and Terry was looking at Emily and smiling.

One of my actions from cycle two was to include recorded music and non-musical activities more often, so that staff and visitors would feel more able to join in with the session. I also found, however, that this provided a greater variety of ways for residents to participate in the session, which sometimes allowed for more engagement from residents. In 
the following example, this resident could not have an instrument unless a staff member played with her, as she would usually put any instruments she was given in her mouth and bite down hard on them. However, when using the parachute we did not encounter this issue:

Moana held the parachute with one hand and I didn't see her bring it to her mouth, and at the end she let go of it easily.

My actions from cycle two included ideas to involve visitors in sessions to a greater degree. However, I found that very few sessions were attended by visitors, and this was usually only for a short part of the session, so I was not able to collect enough data to draw meaningful themes. I think this was partly due to the timing of the sessions, as visitors would be more likely to be busy during the day. I also wondered whether visitors were less likely to come during sessions as they felt that residents would benefit more from a visitor another time when there were no scheduled activities. Some family members took the opportunity to take residents on an outing during their visit.

I also aimed to make a note of popular activities and songs, which others might want to use, and to see if summaries of music therapy notes could be held on file for future reference. As far as I was aware no music therapy notes had been held by the facility previously, but they agreed that it would be useful to have summaries of notes on file for individuals and groups. Some staff members told me that the list of popular activities and songs would be helpful, and that they would use these. Using more recorded music and other activities reduced the necessity of my input in sessions, and I was encouraged by my findings that this may have provided more space for staff and residents to act autonomously.

\section{$\underline{4.4 \text { Summary of findings }}$}

Large group music therapy sessions can draw people together into a shared physical and mental space, where individuals with diverse needs can be included, participate together, and be supported to communicate with others. Flexibility in sessions allows space for participants to be creative and experience self-determination. Group music therapy sessions provide opportunities for moments of connection, which can disrupt the usual patterns of communication and traverse the boundaries between the roles of 'staff' and 'residents'. Participants can also expand these roles to experience musical identities and social rituals together and perform them for the group. 


\section{$\underline{\text { 5. Illustrative Vignette }}$}

I have provided a vignette of my experience of a typical large group session, to illustrate my findings.

I walk into the secure dementia unit and say hello to the residents I pass on my way to the lounge. It is a relatively large unit, with around 15 residents living here permanently and others coming in for day care. Today, as usual, some residents are sitting in the dining room and main lounge areas, and others are walking around the unit. I will be facilitating a 45minute session timed between the end of morning tea and when the caregivers want to begin to move residents into the dining room for lunch. I see that Adam and Leticia are sitting in the dining room, Mary is dozing in the main part of the lounge, and a few residents are sitting in the smaller lounge area. There is an age range of over forty years between the oldest and youngest residents here, and they have varying levels of cognitive and physical ability.

I put my box of percussion instruments down and walk over to the nurses' station where two caregivers are standing. I say hello to them and they smile and say hello. I ask if it's OK to do some music now and they say yes and seem enthusiastic which I am pleased with, as I know how much of a difference their support can make. Tamara in particular is enthusiastic and energetic throughout the session; as I start singing she gives some residents instruments, then encourages other residents to join us by inviting them to stay in the lounge when they walk past. I am very pleased to have her support as I can see how much more the residents respond to the music when a staff member is working with me. It is also much easier to invite residents to join the music session when it is already happening, rather than asking them if they would like to do music soon.

During the session I walk around the group, making eye contact with residents and responding to them through facial expression, tone of voice, movement and music. Sunshine is streaming through the windows, so I suggest singing 'You are my Sunshine', a song which I know most of the residents enjoy. I am also hoping that Tom, a new resident, will be engaged by this song as I have found that it is familiar to people of his age. He is usually stooped over and looking down into his lap, but during this song he looks up at me and seems to have a slight smile. 
We sing a few other well-known older songs, such as 'Daisy, Daisy' and 'It's a Long Way to Tipperary', and I am pleased with the general atmosphere in the session. Several residents are singing along, including Catherine who doesn't often sing, and most residents are playing instruments. Some residents are looking at each other, smiling at each other and playing instruments together.

However, I am aware that these older songs probably do not resonate with the younger residents, some of whom do not seem as engaged. Hoping to provide something for them I sing two more modern songs, 'I Can See Clearly Now' and 'Blowin' in the Wind'. During these songs the older residents who have been singing are less confident, although they continue to play instruments and some still sing along with the choruses. However, one of the younger residents sits forward in her chair and sings along with a lot of energy and emotion, making eye contact with me often. Another younger resident does not seem affected by the music, and I wonder whether to directly approach him. I decide not to as he is fairly new in the unit and I feel that he may benefit from some time to observe the session and experience the music in a less direct way.

Margaret, a long-term resident, talks to me a few times throughout the session whilst I am playing and singing. Her speech is confused and I find it difficult to hear and understand her. I want to continue playing to maintain the structure of the song for the other residents, so I settle for making eye contact and giving her attention whilst she is talking.

In the middle period of the session the energy is high and Tamara invites some residents to dance with her. They dance around the lounge to 'She'll be coming 'round the mountain' while others continue to play and sing. After this it seems that residents are becoming tired; Dot sits down after dancing and sighs, and I see that Mel has closed his eyes. We sing some slower, calmer songs to finish the session.

At this point Francis comes in and sits down. A couple of weeks ago he requested the song 'Paper Roses', which I didn't know but have now learnt. I'm not sure which residents might know or enjoy this song, but I decide to sing the song now that Francis is here and to see how it goes. I have also found that requests from residents are the best way to find songs which many residents will know and enjoy. Francis smiles when I suggest that we do this song, and he sings along, watching me. A few other residents also sing, and so does Tamara, who picks up the lyrics I brought to remind myself and uses them. At the end of the session 
Dot says "I enjoyed that, thank you" and Francis says "see you tomorrow". Several residents say goodbye or wave to me when I leave. 


\section{Discussion}

\subsection{Community music or music therapy?}

Through this research I found that large group music therapy sessions can provide the opportunity for participants to experience a shared social space which enables moments of connection and promotes inclusion, creativity, self-determination, and expanded identities. In reflecting on my music therapy practice during this period, I felt that it was distinct from my previous community music work in three main ways: I had some ability to transition and direct residents between individual and group work, I was able to draw on music therapy theories, and through studying I had increased personal resources and skills to bring to my work.

My community music work was mostly conducted via monthly or fortnightly sessions, as funding allowed. During my placement I was attending my facility three days a week, which provided me with much more time to form relationships with the residents and staff, and to see some residents individually. This gave me greater flexibility in arranging my schedule and in deciding what would be suitable for different residents. For example, a resident in one group at first found it difficult to be in the group space or to connect with others, becoming very anxious and starting to loudly insult or threaten others in the room. I started seeing her for individual sessions as I felt that this protected one-to-one space might help her to feel more secure, and I found that she responded much better in this environment. Staff in the facility wanted her to continue to attend group sessions, as otherwise her social contact would be extremely limited, so we decided on a combination of individual and group sessions. Wood, Verney, and Atkinson (2004) suggest that individual therapy may be a gateway to group therapy, and over time we did see an improvement in her ability to tolerate and participate in group sessions.

O'Grady and McFerran (2007a, 2007b) propose that health can be viewed as a continuum, moving from acute illness or crisis, through rehabilitation and community support to wellbeing. They suggest that for those experiencing acute illness, who are prevented by symptoms or circumstances from being able to function as they normally would, clinical music therapy may be the most suitable approach: 
If the practitioner attempts to use extremely active music techniques when a person is still in the throes of acute illness/crisis they risk disempowering the person by trying to empower them at a time when they are unable to access the inner resources required for the challenges of such active music-making. (O'Grady \& McFerran, 2007a, p. 20)

Community approaches then become more relevant as the person moves along the health-care continuum towards wellbeing. Most residents live in a care home because they are experiencing acute illness and require a high level of care. It could be argued that a clinical approach with individuals or small groups would generally be most appropriate in this setting, due to the high needs of many residents.

However, the authors recognise that limiting the techniques used with a participant may in fact risk unnecessarily pathologising them if they are ready for more. They also acknowledge that it may not be possible to determine objectively where a person is on the health-care continuum. Excluding all community approaches carries an implicit assumption that those experiencing acute illness cannot access the benefits of community and are restricted from experiencing this aspect of wellbeing. In community music therapy wellbeing can be seen as a 'situated process' of being, or feeling, well in a situation (Ansdell \& Stige, 2016, p. 608). There are examples of community music therapy work with participants experiencing acute illness, such as Aasgaard's work with children in paediatric hospital wards, including those with life-limiting illnesses (Aasgaard, 2004). He writes:

A Community Music Therapy approach in the paediatric hospital involves working towards creative networks wider than the patient- therapist dyad also when curative treatment has failed and palliative care takes over. The homo conexus is a being who is 'part of' (networks). Even very sick patients are often capable of doing more than, simply, suffering and being patient; hospital communities must not make people more helpless than necessary. (p. 162)

I felt that even residents who were experiencing an acute level of illness benefitted from large group sessions and the ability to connect with others, even if it was simply through a shared moment of eye contact or touch. Realistically, if only smaller groups were provided then fewer residents would have been able to access music sessions. One of my findings from cycle three was that music brought people together, and this included my observation that some residents who were often tired or had low energy would seem to be encouraged to 
participate by a lively group atmosphere. As discussed in the literature review, there is evidence that staff understanding of residents' abilities, feelings and needs can increase when they see residents participating in music therapy (Broome et al., 2017; Melhuish et al., 2017).

However, I appreciated having the option to include some residents in small group or individual therapy where this seemed appropriate for their needs. Pavlicevic et al. (2015), discussing music therapy in dementia care homes, argue that a focus on individuals with an awareness of the wider context could still be said to be music therapy for the community, as the ripple effect means that individual moments and interventions can ripple out into the wider community. Dennis and Rickson (2014) describe how the music therapy process can move between individual, small group and community music therapy, to suit participants' needs and desires and to support them in different stages of health and illness.

I also recognised the benefits of being able to draw on other music therapy theories alongside community music therapy. In particular, I was interested in music-centred music therapy as a model which aligned well with community approaches. Aigen (2005) describes music-centred music therapy as an approach where 'the musical experience is self-justifying and the primary focus of the therapist's efforts' (p. 49). The experience of the musical process is the therapy, and verbal processing is not necessary. I found music-centred theory particularly helpful when working with residents who had advanced dementia, as the music itself was the place where we could connect and communicate when other forms of communication were difficult or impossible. Aigen contends that music intrinsically creates connection and incorporates the individual within the communal, writing that 'human connection through music' is key to a music-centred approach (p. 90). He also explicitly links a music-centred approach to community music therapy, writing 'Because it is rooted in the commonalities between clinical and non-clinical music-making, it is natural for Community Music Therapy to assume a music-centered [sic] stance' (p. 155).

A music-centred approach seemed to fit with the goals of the residents in the facility, many of whom were motivated to come to music sessions to participate in the music, through listening, singing, playing, requesting songs and more. Aigen writes 'for clients whose desire in music therapy is primarily to participate in music, a music-centered stance can be the most appropriate one to adopt' (Aigen, 2005, p. 92). I saw how successful, enjoyable music experiences motivated residents to participate further in the music therapy group and begin to interact and form relationships with others. Being able to draw on a variety of perspectives in 
different areas of my work strengthened my understanding and ability to provide suitable experiences for residents.

Community music is professionalising, but music therapy has travelled further down this path with protected status in many countries and a more established canon of writing and research (Wood \& Ansdell, 2018). When I was working on community music projects I often had the benefit of collaborating with more experienced colleagues and learning from them. However, finding established writing and research relating to my work was more difficult. When moving into music therapy, the large amount of literature available was extremely helpful to me, alongside the placement experience provided by the music therapy programme. I feel I have benefitted from both experiences, but in music therapy I have a greater feeling of 'standing on the shoulders of giants' and learning from other practitioners.

Hoskyns (2014) compares the student's journey through a music therapy qualification to a quest or 'hero's journey', capturing a sense of personal growth and change through an intensive experience. Part of the hero's journey is to overcome challenges and develop new skills and greater resourcefulness. This reflects my experiences, as over time I became more confident in my abilities and was able to advocate for music therapy in the care home environment. I developed a greater understanding of the pressures faced by staff and was able to suggest and implement changes to create a music therapy programme that was tailored to the care home community as a whole. My own journey into music therapy is just beginning, but I can already see that I have grown significantly from when I started.

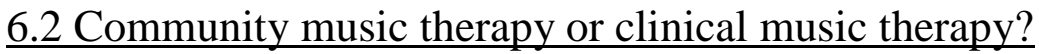

Although I have been drawing on a community music therapy approach, not all aspects of my work were directly informed by this approach and I would not consider myself a 'community music therapist'. As I noted above, I think that being able to draw on other approaches was beneficial to my practice. However, I found that a community approach was relevant to my work, and I think that my large group work was more aligned with community music therapy than clinical music therapy models. In particular, exploring music as milieu and ecological perspectives influenced my thinking and practice.

In my large groups I was focused on creating a supportive environment for communal musicing, rather than achieving specific clinical goals for individual residents. Within a group 
with a more clinical focus, individual goals can be prioritised and used to direct the group activities, and individual assessments may be recommended for this purpose (e.g. Pinson, 2013). However in a community-focused group, aims may be directed at the group more generally, such as enhancing group bonding and feelings of belonging (Pavlicevic, 2003). Whanaungatanga, a sense of connection to others and belonging, is one of the key areas of wellbeing which can be supported by group music therapy.

Stige and Aarø (2012) suggest that in community music therapy music should be seen as more than a means (to change a person's feelings, thoughts or behaviour), or a medium (for actions and interactions), but also as milieu, 'a setting that includes actors engaged in performance and participation' (p. 119). Music creates a social space where those taking part can perform relationships and experience social inclusion. In a large group, a particular music activity is unlikely to act as means or medium for all participants in the same way. However, music can provide a supportive environment for participants to build community together, which was reflected in my findings.

Community music therapy prompted me to take a more ecological view of my work and to consider how the wider environment impacted the residents, rather than just focusing on their diagnoses or individual presentation. Issues which initially seemed secondary, such as where and when sessions took place, were far more important than I realised as the whole environment of the care home had to be accounted for. I realised how much of an impact my sessions could have on staff; music sessions could be an opportunity for fun and connection or they could make it more difficult to carry out daily tasks. I became more aware of the pressures which reinforced the roles of 'staff' and 'resident', and how music could provide opportunities to step outside these identities. I saw for myself how music therapy practice in this context is influenced by 'cultural, clinical, communal, and industrial forces' (Wood, 2016, p. 90). This is not to say that others focusing on different theories would not have been aware of these issues, but for me personally community music therapy was closer to a language I already knew, making these concerns easier to understand.

The questions I developed in each cycle of my research reflect how my perspective widened; moving from a focus on myself and the strategies I was using, to connections within the music therapy group, to dynamics within the facility as a whole. In each cycle community music therapy principles had relevance, both in providing context to what I had observed and encouraging me to look further outwards and increase the scope of what I considered part of 
my music therapy practice. An attitude of continual questioning, motivated initially by personal concerns, led to a community outlook.

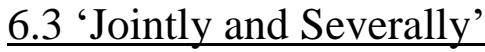

I have identified some aspects of my practice which reflect the differences of a community music and music therapy approach, and ways in which community music therapy principles were relevant to my work. However, rather than attempting to define clear boundaries between the fields of community music and music therapy so that we can remain in our separate territories, I believe a more helpful approach would be to encourage greater collaboration and sharing between our respective disciplines. Although this might seem to threaten our separate identities, particularly in music therapy which has historically fought for greater recognition, through exploring our similarities I believe our points of divergence and unique skill sets will become clearer, helping us to avoid 'unnecessary battles for professional legitimacy' (Tsiris, 2014b, p. 4). Wood and Ansdell (2018) use the analogy of acting 'jointly and severally' (p. 453): being able to work together or autonomously in a shared area of interest and responsibility. Community music therapy reflects a willingness to expand the limits of what we consider music therapy and to learn from other areas.

Widening our practice as therapists and increasing collaboration with others can also provide greater opportunities to the people we are working with. Participants could then experience therapeutic and community-based music-making as appropriate to them, and be supported to move along a therapy to community continuum (Wood et al., 2004) as they move along a health continuum (O'Grady \& McFerran, 2007a), or experience both community and clinical approaches as necessary. The matrix model developed by Wood conceptualises how various 'formats' or modes of music-making, such as individual music therapy or workshops, can be equally important and interconnected, and have therapeutic value for participants (Wood, 2006, 2016).

A flexible approach which responds to local needs and makes use of local resources may result in practitioners collaborating or moving themselves along Aigen's (2012) continuum of traditional music therapy, community music therapy, therapeutic community music, and community music. In this way we can 'follow where people and music lead' (Ansdell, 2014, p. 206), rather than placing boundaries which we will not go beyond, and collaborate with others to provide a range of pathways into different musical experiences. 


\section{$\underline{6.4 \text { Limitations }}$}

This research project was conducted whilst I was a student on placement and therefore was necessarily limited in scope. I only had time to conduct three action research cycles before my placement ended, rather than being able to continue investigating. I also decided to use secondary analysis of data, and therefore to wait until all my data for the cycle was collected before starting analysis. I recognise that this may have reduced my flexibility, however as an inexperienced researcher I wanted to ensure that my process was straightforward and transparent. My actions were also restricted to what I could achieve as a student coming into the facility as an outsider.

\section{$\underline{6.5 \text { Implications for future research }}$}

Large group music therapy work is cost effective and attractive to residential care homes, and further research is recommended exploring the realities of this work and the different approaches which are taken. In particular community music therapy in residential care and dementia care is an area which could be explored further. Research investigating the possibilities for collaboration between music therapists and community musicians would potentially help to encourage greater dialogue in this area. 


\section{Conclusion}

Findings from this research suggest that community music therapy principles can be relevant for large group work with older adults in residential care. In particular, the concept of music as milieu and taking an ecological perspective were especially relevant in my context.

Initially I discovered that it was important to expect the unexpected and allow space for residents to participate in the session in various ways, and that enabling communication through a variety of means provided more opportunities for residents to participate in the session. I found that music sessions provided opportunities for moments of connection, both for residents to connect with each other and for residents to connect with others including staff, and this could disrupt typical patterns of behaviour and interaction. Inclusive musicing supported participants to develop and perform expanded identities and social rituals together. Shared moments between staff and residents traversed role boundaries within a flexible environment that promoted autonomy and self-determination. Experiencing this power of music to draw us into a shared physical, cognitive and emotional space might have encouraged staff to continue music-making with residents.

My large group music therapy practice differed from my previous community music work in a few key ways. I had some ability to transition and direct residents between individual and group work, depending on what seemed to be best suited to their needs. I was able to draw on music therapy theories, including community music therapy and musiccentred music therapy, to gain different perspectives and a deeper understanding of the work. Through the process of studying and spending time on placement I had increased personal resources and skills to bring to my work, and was able to advocate for music therapy in the care home environment.

My impetus for this research came from my concern over whether large open groups for residents with extremely varied needs could be considered a form of music therapy. Through this research I found that these sessions could provide the opportunity for participants, both staff and residents, to experience a shared social space which enabled moments of connection and promoted inclusion, creativity, self-determination, and expanded identities. This suggests that these groups do have therapeutic value, particularly where they are part of a broader spectrum of therapeutic and community-based music experiences. 
There are areas of convergence and points of difference between all professions who work with people in music. There is a temptation, however, for music therapists to isolate themselves from others in a bid to protect the status of the profession. My research suggests that it would be helpful instead to pursue productive ways of working with other professions in order to provide the most appropriate musical support to those who need it, regardless of the forms it takes. 


\section{$\underline{\text { 8. References }}$}

Aasgaard, T. (2004). A Pied Piper among White Coats and Infusion Pumps: Community Music Therapy in a Paediatric Hospital Setting. In M. Pavlicevic \& G. Ansdell (Eds.), Community Music Therapy (pp. 147-163). London, United Kingdom: Jessica Kingsley.

Aigen, K. S. (2005). Music-centered music therapy. Gilsum, NH: Barcelona.

Aigen, K. S. (2012). Community Music Therapy. In G. E. McPherson \& G. F. Welch (Eds.), The Oxford Handbook of Music Education, Volume 2 (2nd ed., pp. 138-154). New York, NY: Oxford University Press.

Aigen, K. S. (2014). The Study of Music Therapy: Current Issues and Concepts. New York, NY: Routledge.

American Music Therapy Association. (2018). Definition and Quotes about Music Therapy. Retrieved from https://www.musictherapy.org/about/quotes/

Ansdell, G. (2002). Community Music Therapy \& The Winds of Change. Voices: A World Forum For Music Therapy, 2(2). doi:https://doi.org/10.15845/voices.v2i2.83

Ansdell, G. (2004). Rethinking Music and Community: Theoretical Perspectives in Support of Community Music Therapy. In M. Pavlicevic \& G. Ansdell (Eds.), Community Music Therapy (pp. 65-90). London, United Kingdom: Jessica Kingsley.

Ansdell, G. (2014). How Music Helps in Music Therapy and Everyday Life. Farnham, United Kingdom: Ashgate.

Ansdell, G., \& Stige, B. (2016). Community Music Therapy. In J. Edwards (Ed.), The Oxford Handbook of Music Therapy (pp. 595-621). Oxford, United Kingdom: Oxford University Press.

Beer, L. E. (2017). The role of the music therapist in training caregivers of people who have advanced dementia. Nordic Journal of Music Therapy, 26(2), 185-199. doi:https://doi.org/10.1080/08098131.2016.1186109

Bolger, L., \& McFerran, K. S. (2013). Demonstrating Sustainability in the Practices of Music Therapists: Reflections from Bangladesh. Voices: A World Forum For Music Therapy, 13(2). doi:https://doi.org/10.15845/voices.v13i2.715

Braun, V., \& Clarke, V. (2006). Using thematic analysis in psychology. Qualitative Research in Psychology, 3(2), 77-101. doi:https://doi.org/10.1191/1478088706qp063oa

Broome, E., Dening, T., Schneider, J., \& Brooker, D. (2017). Care staff and the creative arts: exploring the context of involving care personnel in arts interventions. International 
Psychogeriatrics, 29(12), 1979-1991.

doi:https://doi.org/10.1017/S1041610217001478

Burrows, T. V. (2009). Music as a therapeutic medium for engagement: training to support the well-being of caregivers as well as their cared-for patients. Working With Older People, 13(3), 25-28. doi:https://doi.org/10.1108/13663666200900047

Chen, S.-L., Lin, H.-C., \& Jane, S.-W. (2009). Perceptions of group music therapy among elderly nursing home residents in Taiwan. Complementary Therapies in Medicine, 17(4), 190-195. doi:https://doi.org/10.1016/j.ctim.2009.03.002

Clair, A. A. (2000). The importance of singing with elderly patients. In D. Aldridge (Ed.), Music Therapy in Dementia Care: More New Voices (pp. 81-101). London, United Kingdom: Jessica Kingsley.

Clements-Cortés, A. (2014). Buddy's Glee Club Two: Choral Singing Benefits for Older Adults/Buddy's Glee Club Two : les bénéfices du chant choral auprès des personnes âgées. Canadian Journal of Music Therapy, 20(1), 85-109.

Clements-Cortés, A. (2016). Development and efficacy of music therapy techniques within palliative care. Complementary Therapies in Clinical Practice, 23, 125-129. doi:https://doi.org/10.1016/j.ctcp.2015.04.004

Dennis, P., \& Rickson, D. (2014). The Leader of the Band: A Case Story of Community Music Therapy on a Hospital Ward for People Who Have Dementia. Voices: A World Forum For Music Therapy, 14(1). doi:https://doi.org/10.15845/voices.v14i1.728

Durie, M. H. (1985). A Maori perspective of health. Social Science \& Medicine, 20(5), 483486. doi:https://doi.org/10.1016/0277-9536(85)90363-6

Durie, M. H. (1998). Whaiora: Māori Health Development (2nd ed.). Auckland, New Zealand: Oxford University Press.

Durie, M. H. (2001). Mauri Ora: The dynamics of Māori Health. Melbourne, Australia: Oxford University Press.

Eells, K. (2014). The use of music and singing to help manage anxiety in older adults. Mental Health Practice, 17(5), 10-17. doi:https://doi.org/10.7748/mhp2014.02.17.5.10.e861

Elliott, D. J. (1995). Music Matters: A New Philosophy of Music Education. New York, NY: Oxford University Press.

Elliott, D. J., \& Silverman, M. (2015). Music Matters: A Philosophy of Music Education (2nd ed.). New York, NY: Oxford University Press.

Ensing, H. (2012). Identifying the key values and aims of community music. [Unpublished undergraduate dissertation]. University of Leeds, United Kingdom. 
Eyre, L., \& Lee, J.-H. (2015). Mixed-Methods Survey of Professional Perspectives of Music Therapy Practice in Mental Health. Music Therapy Perspectives, 33(2), 162-181. doi:https://doi.org/10.1093/mtp/miv034

Greenwood, D. J., \& Levin, M. (2007). Introduction to action research: social research for social change (2nd ed.). Thousand Oaks, CA: SAGE.

Higgins, L. (2012). Community Music: In Theory and In Practice. New York, NY: Oxford University Press.

Hoskyns, S. (2014). The Student Practitioner-Researcher as Hero in Her Own Journey - The Value of a Story. Voices: A World Forum For Music Therapy, 14(2). doi:https://doi.org/10.15845/voices.v14i2.777

Hoskyns, S. (2016). Thematic Analysis. In B. L. Wheeler \& K. M. Murphy (Eds.), Music Therapy Research (3rd ed., pp. 563-569). Gilsum, NH: Barcelona.

Hsu, M. H., Flowerdew, R., Parker, M., Fachner, J., \& Odell-Miller, H. (2015). Individual music therapy for managing neuropsychiatric symptoms for people with dementia and their carers: a cluster randomised controlled feasibility study. BMC Geriatrics, 15(1). doi:https://doi.org/10.1186/s12877-015-0082-4

Hurworth, R. (2005). Interpretivism. In S. Mathison (Ed.), Encyclopedia of Evaluation (pp. 209-210). Thousand Oaks, CA: SAGE.

Kitwood, T. (1997). Dementia Reconsidered: The person comes first. Buckingham, United Kingdom: Open University Press.

Klopper, H. (2017). Foreword. In B. McCormack \& T. McCance (Eds.), Person-Centred Practice in Nursing and Health Care: Theory and Practice (2nd ed., pp. xiii-xiv). Chichester, United Kingdom: Wiley Blackwell.

Lesta, B., \& Petocz, P. (2006). Familiar Group Singing: Addressing Mood and Social Behaviour of Residents with Dementia Displaying Sundowning. Australian Journal of Music Therapy, 17, 2-17.

McCormack, B., \& McCance, T. (2017). Introduction. In B. McCormack \& T. McCance (Eds.), Person-Centred Practice in Nursing and Health Care: Theory and Practice (2nd ed., pp. 1-9). Chichester, United Kingdom: Wiley Blackwell.

McDermott, O., Orrell, M., \& Ridder, H. M. (2014). The importance of music for people with dementia: the perspectives of people with dementia, family carers, staff and music therapists. Aging \& Mental Health, 18(6), 706-716. doi:http://doi.org/10.1080/13607863.2013.875124 
McDermott, O., Ridder, H. M., Baker, F. A., Wosch, T., Ray, K., \& Stige, B. (2018). Indirect Music Therapy Practice and Skill-Sharing in Dementia Care. Journal of Music Therapy, 55(3), 255-279. doi:https://doi.org/10.1093/jmt/thy012

McFerran, K. S., \& Rickson, D. (2014). Community music therapy in schools: Realigning with the needs of contemporary students, staff and systems. International Journal of Community Music, 7(1), 75-92. doi:https://doi.org/10.1386/ijcm.7.1.75_1

Melhuish, R., Beuzeboc, C., \& Guzmán, A. (2017). Developing relationships between care staff and people with dementia through Music Therapy and Dance Movement Therapy: A preliminary phenomenological study. Dementia, 16(3), 282-296. doi:https://doi.org/10.1177/1471301215588030

Mendes, A. (2015). 'Unlocking' people with dementia through the use of music therapy. Nursing and Residential Care, 17(9), 512-514. doi:https://doi.org/10.12968/nrec.2015.17.9.512

Ministry of Health. (2013). New Zealand Framework for Dementia Care. Retrieved from https://www.health.govt.nz/system/files/documents/publications/new-zealandframework-for-dementia-care-nov13.pdf.

Ministry of Health. (2015). Māori health models. Retrieved from https://www.health.govt.nz/our-work/populations/maori-health/maori-health-models Ministry of Health. (2017). Health and Independence Report 2016: The Director-General of Health's Annual Report on the State of Public Health. Retrieved from https://www.health.govt.nz/system/files/documents/publications/health-independencereport-2016-apr17.pdf.

Ministry of Health. (2018). Health and Independence Report 2017: The Director-General of Health's Annual Report on the State of Public Health. Retrieved from https://www.health.govt.nz/system/files/documents/publications/health-andindependence-report-2017-v2.pdf.

Music Therapy New Zealand. (2011). What is music therapy? Retrieved from http://www.musictherapy.org.nz/

Music Therapy New Zealand. (2012). Code of Ethics for the Practice of Music Therapy in New Zealand. Retrieved from http://www.musictherapy.org.nz/wpcontent/uploads/downloads/2013/02/Code-of-Ethics-2012.pdf

Nowell, L. S., Norris, J. M., White, D. E., \& Moules, N. J. (2017). Thematic Analysis: Striving to Meet the Trustworthiness Criteria. International Journal of Qualitative Methods, 16(1), 1-13. doi:https://doi.org/10.1177/1609406917733847 
O'Grady, L., \& McFerran, K. (2007a). Community Music Therapy and Its Relationship to Community Music: Where Does It End? Nordic Journal of Music Therapy, 16(1), 1426. doi:https://doi.org/10.1080/08098130709478170

O'Grady, L., \& McFerran, K. (2007b). Uniting the Work of Community Musicians and Music Therapists through the Health-Care Continuum: A Grounded Theory Analysis. Australian Journal of Music Therapy, 18, 62-86.

Pavlicevic, M. (2003). Groups in music. London, United Kingdom: Jessica Kingsley. Pavlicevic, M. (2010). Let the Music Work: Optimal Moments of Collaborative Musicing. In B. Stige, G. Ansdell, C. Elefant, \& M. Pavlicevic (Eds.), Where Music Helps: Community Music Therapy in Action and Reflection (pp. 99-112). Farnham, United Kingdom: Ashgate.

Pavlicevic, M. (2012). Between Beats: Group Music Therapy Transforming People and Places. In R. MacDonald, G. Kreutz, \& L. Mitchell (Eds.), Music, Health and Wellbeing (pp. 196-212). New York, NY: Oxford University Press.

Pavlicevic, M., \& Ansdell, G. (2004). Introduction: 'The Ripple Effect'. In M. Pavlicevic \& G. Ansdell (Eds.), Community Music Therapy (pp. 15-31). London, United Kingdom: Jessica Kingsley.

Pavlicevic, M., Tsiris, G., Wood, S., Powell, H., Graham, J., Sanderson, R., . . Gibson, J. (2015). The 'ripple effect': Towards researching improvisational music therapy in dementia care homes. Dementia, 14(5), 659-679. doi:https://doi.org/10.1177/1471301213514419

Pinson, J. (2013). Involving Senior Citizens in Group Music Therapy. London, United Kingdom: Jessica Kingsley.

Powell, H. (2004). A Dream Wedding: From Community Music to Music Therapy with a Community. In M. Pavlicevic \& G. Ansdell (Eds.), Community Music Therapy (pp. 167-185). London, United Kingdom: Jessica Kingsley.

Procter, S. (2004). Playing Politics: Community Music Therapy and the Therapeutic Redistribution of Musical Capital for Mental Health. In M. Pavlicevic \& G. Ansdell (Eds.), Community Music Therapy (pp. 214-230). London, United Kingdom: Jessica Kingsley.

Putnam, R. D. (2000). Bowling Alone. New York, NY: Simon \& Schuster.

Ray, K. D., \& Fitzsimmons, S. (2014). Music-assisted bathing: making shower time easier for people with dementia. Journal of Gerontological Nursing, 40(2), 9-13. doi:https://doi.org/10.3928/00989134-20131220-09 
Schippers, H. (2018). Community Music Contexts, Dynamics, and Sustainability. In B.-L. Bartleet \& L. Higgins (Eds.), The Oxford Handbook of Community Music (pp. 23-42). New York, NY: Oxford University Press.

Small, C. (1998). Musicking: The Meanings of Performing and Listening. Middletown, CT: Wesleyan University Press.

Smith, J. K. (2008). Interpretive Inquiry. In L. M. Given (Ed.), The SAGE Encyclopedia of Qualitative Research Methods (pp. 459-461). Thousand Oaks, CA: SAGE.

Statistics New Zealand. (2016). National Population Projection: 2016 (base)-2068. Retrieved from https://www.stats.govt.nz/information-releases/national-population-projections2016base2068

Steele, M. E. (2016). How Can Music Build Community? Insight from Theories and Practice of Community Music Therapy. Voices: A World Forum For Music Therapy, 16(2). doi:https://doi.org/10.15845/voices.v16i2.876

Stige, B. (2004). Community Music Therapy: Culture, Care and Welfare. In M. Pavlicevic \& G. Ansdell (Eds.), Community Music Therapy (pp. 91-113). London, United Kingdom: Jessica Kingsley.

Stige, B. (2010). Musical Participation, Social Space, and Everyday Ritual. In B. Stige, G. Ansdell, C. Elefant, \& M. Pavlicevic (Eds.), Where Music Helps: Community Music Therapy in Action and Reflection (pp. 125-147). Farnham, United Kingdom: Ashgate.

Stige, B. (2012). Elaborations Toward a Notion of Community Music Therapy. Gilsum, NH: Barcelona.

Stige, B., \& Aarø, L. E. (2012). Invitation to Community Music Therapy. New York, NY: Routledge.

Stige, B., Ansdell, G., Elefant, C., \& Pavlicevic, M. (2010). When Things Take Shape in Relation to Music: Towards an Ecological Perspective on Music's Help. In B. Stige, G. Ansdell, C. Elefant, \& M. Pavlicevic (Eds.), Where Music Helps: Community Music Therapy in Action and Reflection (pp. 277-308). Farnham, United Kingdom: Ashgate.

Stige, B., \& McFerran, K. S. (2016). Action Research. In B. L. Wheeler \& K. M. Murphy (Eds.), Music Therapy Research (3rd ed., pp. 429-440). Dallas, TX: Barcelona.

Terry, G., Hayfield, N., Clarke, V., \& Braun, V. (2017). Thematic Analysis. In C. Willig \& W. Stainton-Rogers (Eds.), The SAGE Handbook of Qualiative Research in Psychology (2nd ed., pp. 17-37). Thousand Oaks, CA: SAGE. 
Tsiris, G. (2014a). Community Music Therapy [Special issue]. International Journal of Community Music, 7(1).

Tsiris, G. (2014b). Community music therapy: Controversies, synergies and ways forward. International Journal of Community Music, 7(1), 3-9.

doi:https://doi.org/10.1386/ijcm.7.1.3_2

Tuckett, A. G., Hodgkinson, B., Rouillon, L., Balil-Lozoya, T., \& Parker, D. (2015). What carers and family said about music therapy on behaviours of older people with dementia in residential aged care. International Journal of Older People Nursing, 10(2), 146-157. doi:http://doi.org/10.1111/opn.12071

Wood, S. (2006). "The Matrix": A Model of Community Music Therapy Processes. Voices: A World Forum For Music Therapy, 6(3). doi:https://doi.org/10.15845/voices.v6i3.279

Wood, S. (2016). A Matrix for Community Music Therapy Practice. Dallas, TX: Barcelona.

Wood, S., \& Ansdell, G. (2018). Community Music and Music Therapy: Jointly and Severally. In B.-L. Bartleet \& L. Higgins (Eds.), The Oxford Handbook of Community Music (pp. 453-476). New York, NY: Oxford University Press.

Wood, S., Verney, R., \& Atkinson, J. (2004). From Therapy to Community: Making Music in Neurological Rehabilitation. In G. Ansdell \& M. Pavlicevic (Eds.), Community Music Therapy (pp. 48-62). London, United Kingdom: Jessica Kingsley. 
Appendix 1: Facility information sheet and consent form

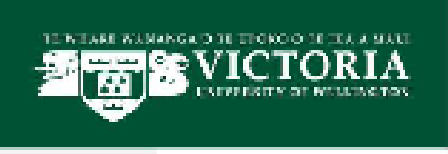

TE KÖKI NEW ZEALAND SCHOOL OF MUSIC

VICTORIA UNIERSITY OF WELIINGTON, PO Box 600, Welingion 6140, New Zealand

Phone + 64-4463-5369 Email musicgnazm.sc.nz Web www.nzsm.sc.nz

\section{Master of Music Therapy Research Project}

\section{How can I use community music therapy principles to improve my practice with large groups of older adults in a residential care facility?}

\section{INFORMATION SHEET}

Dear [clinical liaison],

I am writing to ask for permission to review my clinical notes and records that I am keeping during my placement at [facility] for my Masters research. I may also ask for your help in approaching families for informed consent should an example of work with a particular resident be needed. My research project is being supervised by [supervisor] and [supervisor] at Victoria University of Wellington.

I am researching my own music therapy practice on placement, in order to improve my practice and to inform other music therapists and students. The title of my project is: 'How can I use community music therapy principles to improve my practice with large groups of older adults in a residential care facility?'. I am going to research how I facilitate large group sessions, in order to improve my practice. I will use the principles of a Community Music Therapy approach to guide these improvements.

The data generated from reviewing my clinical notes will be analysed along with data from other sources, to answer my research question. No real names of residents or of the facility will be used in the final written project, and every effort will be made to avoid including identifying details. However, the music therapy community in New Zealand is small, so it is possible that someone may identify where the research has taken place or may identify individual residents from what is written. No raw data that includes real names or identifying details will be shown to anyone outside of [facility].

The data will be used for analysis in order to answer my research question. All data and resulting analysis will be stored on a password-protected computer or password-protected USB memory stick. All written records and consent forms for this research will be stored in a locked cupboard at the New Zealand School of Music. All records will be kept for ten years and access will be restricted to the researcher and her supervisors. After ten years it will be destroyed. 
A summary of the project findings will be provided to [facility] once the research is completed. A copy of the final exegesis will be published in the library at Victoria University, and findings may be submitted to other relevant journals or conferences.

You are under no obligation to give your permission for the data to be used for research purposes. If you decide to allow it to be used, you have the right to:

- Ask any questions about the study at any time until it is completed.

- Withdraw information from the research up until the end of the data analysis at the end of October.

- Be given a summary of the project findings when it is concluded.

Please contact the researcher or supervisors if you have any questions about the project.

- Researcher: Hazel Barrett

Email:

- Supervisor:

Email:

- Supervisor:

Email:

This project has been reviewed and approved by the New Zealand School of Music Postgraduate committee. The Victoria University of Wellington Human Ethics Committee has given generic approval for music therapy students to conduct studies of this type (Ethics Approval: 22131). The music therapy projects have been judged to be low risk and, consequently, are not separately reviewed by any Human Ethics Committees. The supervisors named above are responsible for the ethical conduct of this research. If you have any concerns about the conduct of this research, please contact the supervisors or, if you wish to raise an issue with someone other than the student or supervisors, please contact the Victoria University of Wellington Human Ethics Convenor AProf Susan Corbett, email susan.corbett@vuw.ac.nz, telephone 044635480.

If you agree that I can use my clinical notes and records created at [facility] during my placement for my research, please sign both copies of the enclosed consent form and return one to me.

Many thanks,

Hazel Barrett 


\section{Master of Music Therapy Research Project}

How can I use community music therapy principles to improve my practice with large groups of older adults in a residential care facility?

\section{CONSENT FORM}

- I have read the information sheet and have obtained sufficient information about the study.

- I understand that from the review of clinical notes residents' real names and details will not be used in any publication or presentation arising from this research.

- I understand that informed consent will be sought from families should a particular case example be used to illustrate the findings.

- I understand that research data will be kept for ten years and will be stored securely at the New Zealand School of Music and/or on a password-protected computer or password-protected USB memory stick.

- I understand that I can withdraw information from the research up until the end of October 2018.

- I acknowledge that the study will be published in the library at Victoria University and may be presented at conferences and/or in published papers.

- I understand that I can contact the researcher or research supervisors [supervisor] and [supervisor] if I have any concerns or questions relating to the research.

- I also understand that I can contact the Victoria University of Wellington Human Ethics Convenor Susan Corbett if I have any other concerns about this research.

I therefore consent to Hazel Barrett reviewing clinical notes and records that are kept during her placement at [facility] for her research.

Signed Date: 
Appendix 2: Coding example

(3) 日/5=

Cycle 2 Analysis.nvp - NVivo Pro

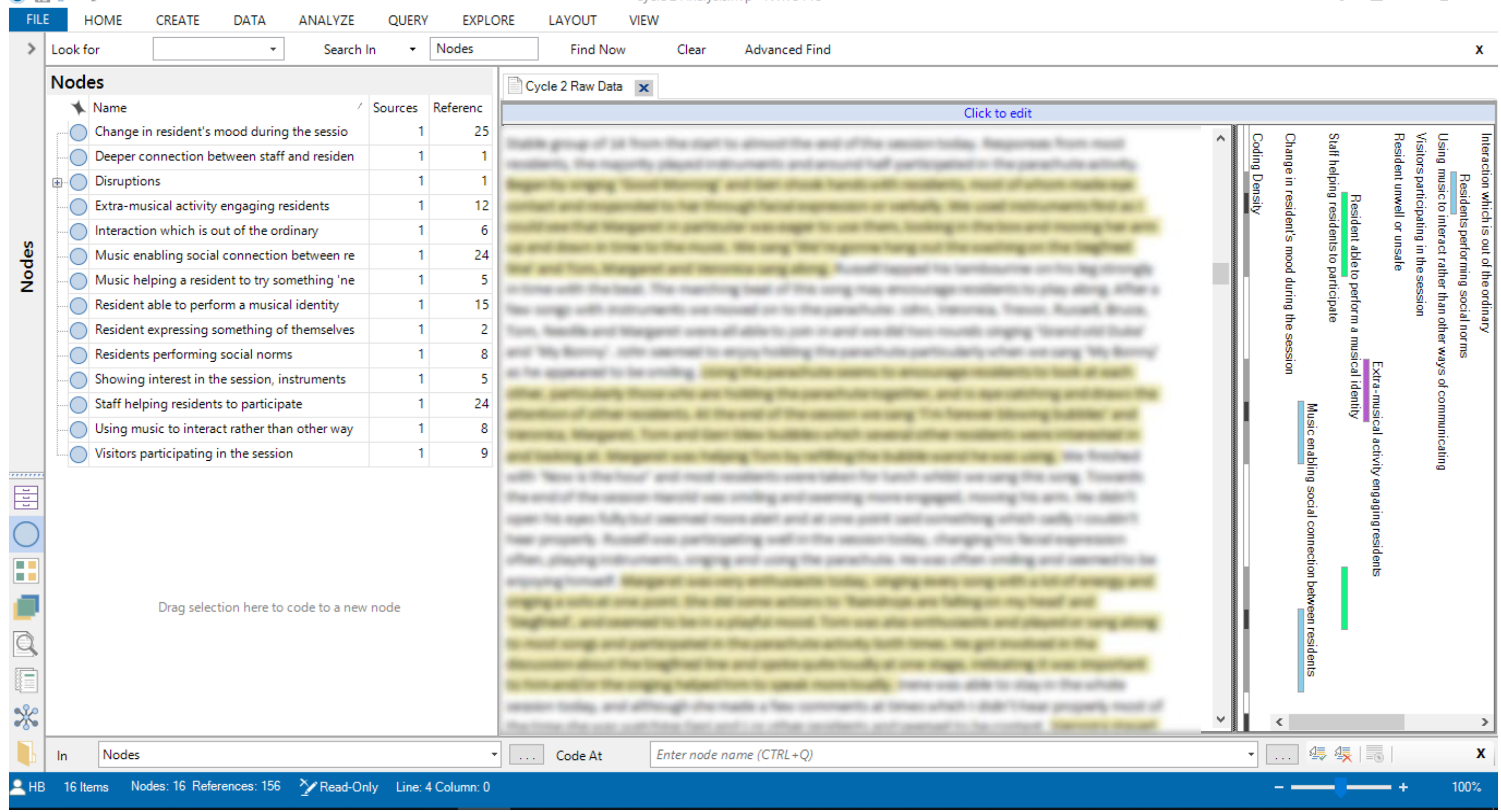




\section{Appendix 3: Detail of the thematic analysis process in each action cycle}

\section{Cycle 1}

During cycle one I wanted to gain a baseline of normal practice and to give myself time to adjust to the facility before taking on new challenges, so I had no specific actions for this cycle. I collected data from all four group sessions for five weeks before starting analysis. During the analysis most codes were generated initially to describe a certain interesting data item, then on further readings I would gather more data for this code. As the analysis progressed I looked through the data focusing on a particular code or group of codes, to ensure that relevant data had not been overlooked. I also kept notes as I went on how the codes might relate to each other, ideas for potential themes, and potential actions. In this cycle I felt that some of my codes were not descriptive enough, making them too generic and not as useful when compiling themes, and I attempted to improve on this in the next cycle.

Once I was approaching saturation point and finding fewer new codes or data extracts I started refining the codes into themes. To do this I bypassed those which were not well supported by the data, combined those which seemed to be different expressions of the same idea (for example 'social gesture' and 'social contact between residents') and looked into categories which contained a large number of data extracts to develop these in more detail. In developing the themes I also focused on my interpretation of the data and points which I felt were important to develop, rather than simply attempting to describe the data. In this way the analysis reflects my interpretation of the data, and my interests for the next cycle, prompted by my exploration of the data. For example, I had a code of 'disruptions' to the session in this cycle, such as residents being given medicines or food and drink. Although I felt my response to these disruptions could be an interesting area to investigate, I did not feel that I had written enough about these incidences to draw any conclusions. Therefore I decided not to develop a theme using this code but to flag it as a potential area for investigation in cycle two.

There was some overlap between refining the themes and the coding, as an idea of a potential theme might prompt me to consider another aspect to code. As I finalised my themes I compared them to the data extracts from each relevant code and the notes I had taken when initially reading through the data. I also related them to relevant aspects of the community music therapy literature, to further develop my ideas. 


\section{Cycle 2}

During cycle two I incorporated the actions from cycle one into my practice. At first I found this difficult and I did not always remember to include these changes in my sessions. I decided to write the actions on a sticky note on my computer, so that I would see them when I was writing notes and planning sessions. This seemed to be effective and helped me to include the actions in my practice as I had regular reminders. By the end of the cycle I felt that the actions were now embedded in my practice, as they felt natural and I did not need to make a conscious effort to remember them.

I decided to start data collection a week after I finished analysis for cycle one, so that the actions had started to become evident in my practice. In cycle one I was able to use the notes from four group sessions, however between cycle one data collection and cycle two the numbers in one group reduced and during cycle two there were consistently around five participants in this group. I felt that this could no longer be considered a large group and therefore was not relevant to my question, so this data was not included in the cycle two analysis. Due to this change I extended the data collection to six weeks in order to be certain that I had enough data which would be representative of typical practice.

Another change for cycle two was that I made some alterations to my schedule. This resulted in the groups being held fewer times each week, but each session was longer and I had more time to write in-depth notes after the session. I think that my resulting data contained more detail about the groups and more considered reflections, which hopefully improved the significance of my findings.

I followed the same process for the thematic analysis as in cycle one: first I read through the data making notes, then focused on inductive coding, and finally refined and compiled the codes into themes. From my analysis in cycle one I learned to make my codes more descriptive and less generic. I also noticed in cycle one that 'disruptions' might be an interesting area to investigate, so I started cycle two analysis with this in mind as a potential area to code. In my code for disruptions I found that there were two main categories: 'other activities being carried out' and 'resident unwell or unsafe'. The former had only a few instances and these included morning tea or residents arriving and leaving during the session. The later contained the most instances of disruptions, where generally I needed to ask a caregiver to help a resident and therefore the session was disrupted. Disruptions overall were minimal, partly due to the new schedule which was developed in consultation with care staff. 
Therefore I felt that it was not necessary to generate any actions relating to session disruptions.

\section{Cycle 3}

In cycle three I again reminded myself of my actions with a sticky note, and I felt that this was successful in reminding me to include these in my practice. As before I left a short gap before starting data collection, to have some time to remember and adjust to the new actions. I included data up until the end of my placement, resulting in a total of 27 sessions with 15 in the secure dementia wing over seven weeks. Although a core group of residents had continued living in the secure area throughout my placement, several residents had left and others had arrived, changing the group dynamic over time. No changes were made to my schedule during this time.

I followed the same process for thematic analysis as in cycles one and two, although I read through the data for each group separately in this cycle as I thought it might be helpful to differentiate between groups further. However, as in previous cycles I found that almost all codes were supported by data from all three groups, and all themes were represented in each group. 